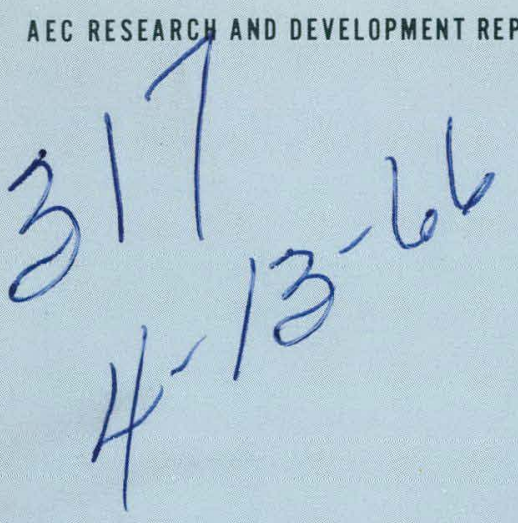

J. E. Harrell

\title{
MIXING OF FLUIDS IN SMALL-DIAMETER \\ TANKS BY RECIRCULATION (U)
}

\section{UNION CARBIDE CORPORATION}

\section{NUCLEAR DIVISION}

\section{OAK RIDGE Y-12 PLANT}

operated for the ATOMIC ENERGY COMMISSION under U. S. GOVERNMENT Contract W-7405 eng 26

UNION

CARBIDE
OAK RIDGE Y-12 PLANT

P. O. BOX $Y$

OAK RIDGE, TENNESSEE 37831 


\section{DISCLAIMER}

This report was prepared as an account of work sponsored by an agency of the United States Government. Neither the United States Government nor any agency Thereof, nor any of their employees, makes any warranty, express or implied, or assumes any legal liability or responsibility for the accuracy, completeness, or usefulness of any information, apparatus, product, or process disclosed, or represents that its use would not infringe privately owned rights. Reference herein to any specific commercial product, process, or service by trade name, trademark, manufacturer, or otherwise does not necessarily constitute or imply its endorsement, recommendation, or favoring by the United States Government or any agency thereof. The views and opinions of authors expressed herein do not necessarily state or reflect those of the United States Government or any agency thereof. 


\section{DISCLAIMER}

Portions of this document may be illegible in electronic image products. Images are produced from the best available original document. 
Printed in USA. Price \$3.00. Available from the Clearinghouse for Federal Scientific and Technical Information, National Bureau of Standards, U.S. Department of Commerce, Springfield, Virginia

\section{LEGAL NOTICE}

This report was prepared as an account of Government sponsored work. Neither the United States, nor the Commission, nor any person acting on behalf of the Commission:

A. Makes any warranty or representation, expressed or implied, with respect to the accuracy, completeness, or usefulness of the information contained in this report, or that the use of any information, apparatus, method, or process disclosed in this report may not infringe privately owned rights; or

B. Assumes any liabiliries with respect to the use of, or for damages resulting from the use of any information, apparatus, method, or process disclosed in this report.

As used in the above, "person acting on behalf of the Commission" includes any employee or contractor of the Commission, or employee of such contractor, to the extent that such employee or contractor of the Commission, or employee of such contractor prepares, disseminates, or provides access to, any information pursuant to his employment or contract with the Commission, or his employment with such contractor. 

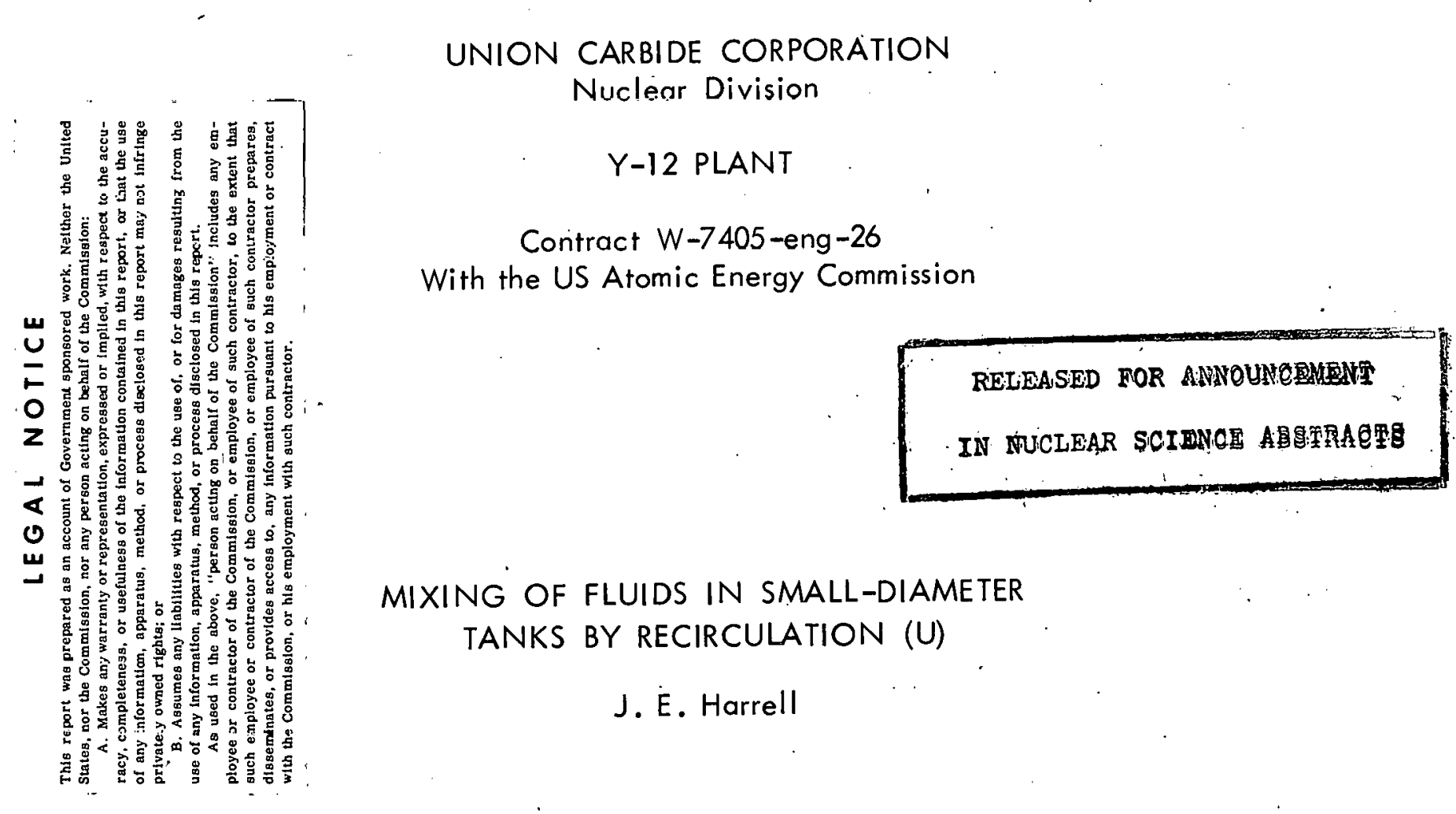

This report is based on a study by the author as partial fulfillment of requirements for the degree of Master of Science in Chemical Engineering from The University of Tennessee.

Oak Ridge, Tenness̀ee 
Distribution:

\begin{tabular}{|c|c|c|c|}
\hline Ackerson, R. D. & (AFSC) & Lewis, F. O. & (ORGDP) \\
\hline Bailey, E. W. & $r$ & McLendon, J. D. & , \\
\hline Ballenger, H.F. & (2) & Mitchel, G. W. & \\
\hline Burkhart, L. E. & & Patton, F. S. & \\
\hline Center, C. E. & (ORGDP) & Rader, D. H. & \\
\hline Christman, A. M. & $\because \quad \cdot$ & Reece, J. S. & \\
\hline Cowen, D. D. & (ORNL) & Schwenn, M. F. & \\
\hline Dow, Neal & & Trotter, T. C. & \\
\hline Harrell, J.E. & $(15)$ & Waters, J. L: & . \\
\hline Harwell, W. L. & $($ ORGDP $)(5)$ & Whitson, W. K. : & \\
\hline Hemphill, L. F. & & Winkel, R. A. & (Paducah) \\
\hline Huber, A. P. & (ORGDP) & Zurcher, E. & \\
\hline Keller, C. A. & $(A E C-O R O)(4)$ & Y-12 Central Files & (5) \\
\hline Kite, H. T. & & Y-12 Central Files & $(Y-12 R C)$ \\
\hline
\end{tabular}

In addition, this report is distributed in accordance with the category Waste Disposal and Processing, as given in the "USAEC Standard Distribution Lists for Unclassified Scientific and Technical Reports", TID-4500. 


\section{ABSTRACT}

- A theoretical treatment for the intermixing of fluid, resulting from recirculation in small-diameter tanks of large length-to-diameter ratio, was made. By applying a diffusional-type mixing model, relationships were developed for predicting the mixing time needed to disperse a tracer pulse to a small level of inhomogeneity with a system bulk contents. A linear correlation between the logarithm of the dimensionless mixing time and the logarithm of the system mixing number for a given small level of inhomogeneity was found to exist for mixing numbers less than 0.1 .

Experimental determinations of dispersion intensity and mixing time were made for tanks with length-to-diameter ratios up to 50. Significant departures were observed in a comparison of measured uild published (obtained for very long. straight lines) dispersion intensity data for Reynolds numbers less than about 20,000.

Predicted mixing time based upon the developed mixing theory was found to compare favorably with measured mixing times when measured dispersion intensity data were applied, but to generate large relative errors when published dispersion data were used. 


\section{ACKNOWLEDGEMENTS}

The author would like to express appreciation to all those at the $Y-12$ Plant, Union Carbide Corporation-Nuclear. Division, whose help made this study possible, and particularly to I. G. Speas and F. S. Patton of the Engineering Division and H. T. Kite and G. B. Marrow of the Development Division who made arrangements for the study. The author wishes to thank $Y-12$ Plant Maintenance Division personnel who built and modified the experimental facility, Dr. A. A. Brooks and M. H. Noojin of the Oak Ridge Gaseous Diffusion Plant Central Data Processing Division who wrote the computer programs, Dr. D. A. Gardiner and T. L. Hebble of the Oak Ridge National Laboratory Mathematics Division who provided guidance in the statistical analysis of the data, and G. A. Grooms of the Y-12 Chemical Engineering Development Department who assisted in the experimental program.

For enthusiastic and financial support of the study, the author expresses gratitude to D. E. George, J. E. Lovett, and E. L. Keller of the United States Atomic Energy Commission.

For his helpful suggestions and guidance as his major professor, the author wishes to thank Dr. J. J. Perona.

Finally, thanks are extended to the Technical'Reports Department for advice and assistance in the preparation of this manuscript. 


\section{'TABLE OF CONTENTS}

CHAPTER

PAGE

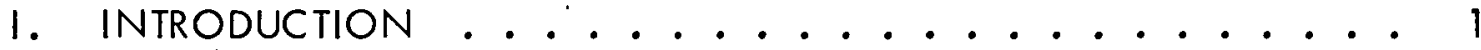

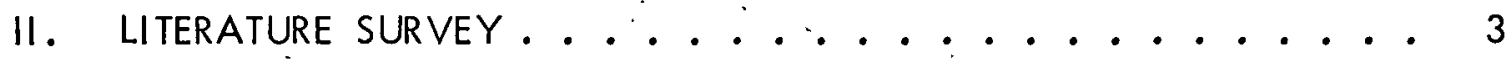

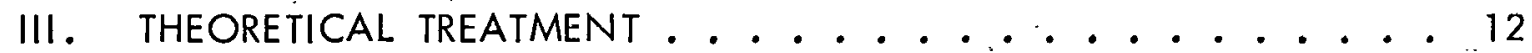

IV. EXPERIMENTAL FACILITY . . . . . . . . . . . . . 29

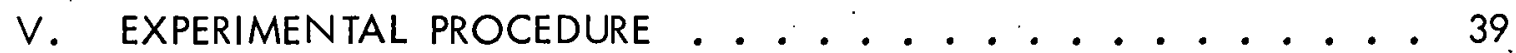

VI. ANALYSIS AND DISCUSSION OF RESULTS . . . . . . . 42

Dispersion Intensity Data . . . . . . . . . . 42

Mixing-Time Data . . . . . . . . . . . 52

Comparison of Theoretical and Experimental Mixing Times . . . 69

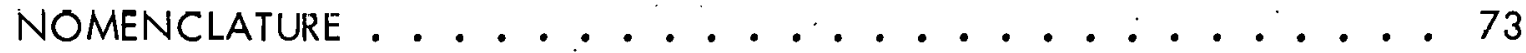

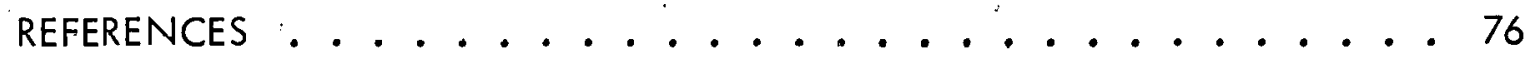

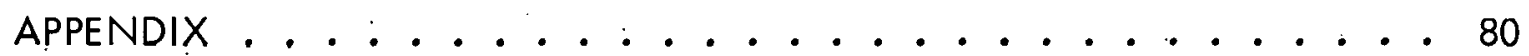

METHOD FOR TRANSFORMING ELECTRICAL CONDUCTIVITY DISTRIBUTIONS INTO DISPERSION INTENSITIES . . . . . . 81 


\section{LIST OF TABLES}

TABLE

PAGE

1. Predicted Dimensionless Mixing Time as a Function of the Mixing Number.................. . . 25

11. Correlation Coefficients and Error Estimates for the CorrelationsDimensionless Mixing Time-Mixing Number . . . . . . . 27

111. Characteristic Pipe Lengths and Component Volumes for the Tank Loop Systems Studied . . . . . . . . . . . . . 38

IV. Correlation Coefficients and Error Estimates for the Experimental Dimensioned Variance-Recirculation Rate Correlations . . . . 48

V. Analysis of Variance Table for Hypothesis That All Data Can Be Represented by a Single Dispersiun liilensity-Reynolds Number Correlation .............. . . . 51

VI. Experimental Mixing Time and Dimensioned Variance Data Tabulation ... . . . . . . . . . . 55

VII. Correlation Constants and Error Estimates for the Experimental Mixing Time-Recirculation Rate Correlations . . . . . . 67 . 


\section{LIST OF FIGURES}

FIGURE

PAGE

1. Experimental Dispersion Intenisity-Reynolds Number CorreIation with Comparison to Taylor's Prediction and Published Data .......................

2. Linear Correlations to Predicted Dimensionless Mixing TimeMixing Number Data for Seven Mixed Conditions . . . . . 26

3. Representative Arrangement for Experimental Tank Loop Systems . 30

4. Tracer Addition Piping. . . . . . . . . . . . 31

5. Mockup of a Conductivity Cell Mounted in a Two-Inch Tee at the Tank Outlet ............ 33

6. Mockup of a Conductivity Coll Mounted at the Tank. Dutlet in a Reducer . . . . . . . . . . . 34

7. Mockup of a Conductivity Cell Mounted within a Tank Onto a Six by Six by Two-Inch Tee .......... 35

8. The Experimental Facility ........... 37

9. Typical Recorder Strip Chart Obtained at a Relatively. High Recirculation Rate and at the Tank Outlet (Run 23, Series 8 at 91.5 G.P.M.)............. 44

10. Typical Recorder Strip Chart Obtained at a Relatively Low Recirculation Rate and at the Tank Inlet (Run 61, 
11. Typical Correlation Between Dimensioned Variance and the Recirculation Rate as Shown for Series 6 (Table VI) • . . . 49

12. Experimental and Predicted Mixing Times as Functions of the Recirculation Rate for Series 1 (Table VI). . . . . . . 60

13. Experimental and Predicted Mixing Times as Functions of the Recirculation Rate for Series 3 (Table VI). ....... 61

14. Experimental and Predicted Mixing Times as Functions of the Recirculation Rate for Series 6 (Table VI). . . . . . . 62

15. Experimental and Predicted Mixing Times as Functions of the Recirculation Rate for Series 8 (Table VI). . . . . . . 63

16. Experimental and Predicted Mixing Times as Functions of the Recirculation Rate for Series 11 (Table VI) . . . . . . 64

17. Experimental and Predicted Mixing Times as Functions of the Recirculation Rate for Series 24 (Table VI) . . . . . . 65

18. Experimental and Predicted Mixing Times as Functions of the Recirculation Rate for Series 26 (Table VI) . . . . . . 66

19. Experimental and Predicted Mixing Times at a Mixed Condition of 0.90 as Functions of the Recirculation Rate for

Series 1 . . . . . . . . . . . . . 71 


\section{CHAPTER $\quad$.}

\section{INTRODUCTION}

- Since the inception of nuclear materials processing in the early 1940's, the mixing of fluids contained in cylindrical tankage of large length-to-diameter ratio, as is found in nuclear fuel processing plants, has received little attention. Due to the nature of operations in a processing plant, fuel solutions are generated at irregular intervals, with varying composition and concentration, and stored to await final processing. As these solutions are transferred to a tankage facility, they tend not to intermix but to separate according to their specific gravities. When tank contents need to be homogenized for further processing or fuel inventory, recirculation mixing is frequently used; however, since this operation has not been studied to determine the relationship between the mixing variables, recirculation mixing has remained an art.

As tankage geometry is restricted by the nuclear physics of the material in storage, tankage with relatively small diameter (usually less than 5 inches) and large length is required. The most common installation consists of a single horizontal tank, with a length-to-diameter ratio ranging between 20 and 150, slightly inclined for drainage, and equipped with a piping loop including a pump for mixing by recirculation. Although a knowledge of the mixing characteristics is essential if representative samples are to be obtained for accountability purposes, an 
analysis of the intermixing which accompanies recirculation has not been presented in the literature.

At the request of the Division of Nuclear Materials Management of the United States Atomic Energy Commission, a program was undertaken at the $Y-12$ Plant, operated by the Union Carbide Corporation for the United States Atomic Energy Commission, to investigate fluid mixing in the most common types of cylindrical tankage currently used for storage of enriched uranium and plutonium solutions. After a survey of many processing facilities within the Commission complex and a survey of both published and unpublished literature, a progress report ${ }^{(1)\left({ }^{*}\right)}$ was presented which provided a basis for the subsequent program. In the near future, another progress report ${ }^{(2)}$ on the experimental activities and theoretical accomplișments, considering various tankage configurations and mixing schemes, will be issued.

The objective of this thesis is to present a theoretical treatment for single tank recirculation mixing, based on a diffusional model, and demonstrate its applicability by comparison with acquired experimental data.

${ }^{(*)}$ Superscripts throughout this thesis refer to the references as listed on Page 77. 


\section{CHAPTER II}

\section{LITERATURE SURVEY}

In recent years numerous articles that deal with the intermixing of fluids during flow have been written. The motivation for most has been to bridge the extreme and sometimes inapplicable assumptions concerning the mixed condition of fluid during continuous flow through process equipment. Although an assumption of instantaneous and complete mixing may be warranted for some vigorously agi tated reactor vessels or an assumption of "plug flow" adequate to describe transport through some heat exchangers, packed, towers, extraction columns, and the like, the real physical situation must lie between these limits. The effect of intermixing during flow is to reduce mass and energy transport driving potentials below that for "plug flow." For chemical reactions that are temperature and concentration dependent, the effect of intermixing is complex and highly significant.

A diffusional-type mixing model and a tanks-in-series mixing model are the two most frequently used to describe fluid intermixing. When the deviation from "plug flow" is small it has been argued that by virtue of the random motion of molecules and the existence of turbulent eddies, a diffusional-type model can be appropriately applied. However, under conditions to be discussed; a limiting situation exists where either of the models can be used. The utility of either model depends upon the predictability of the parameters embodying the degree of mixing as a function of the dynamics of flow and characteristic system dimensions. This 
parameter for the diffusional model has been termed the dispersion intensity. Its functional relationship and usefulness for both models will be considered.

A comprehensive review of fluid intermixing has been made in an article by Levenspiel and Bischoff.

For a section of pipe where fluid intermixing can be treated by use of the diffusional analogy; a differential material balance for conservation of mass for: any component can be written. This material balance, as discussed by Jost, (4) must include both a diffusive flux and a convective flux. To account for the injection of a quantity of any component into the stream, another term must be added, as introduced by Bischoff. ${ }^{(5)}$ The general form of the dispersion equation becomes:

$$
\nabla \cdot(D \nabla c)-(\bar{v} \cdot \nabla) c-\frac{\partial c}{\partial t}+S=0
$$

where:

$$
\begin{aligned}
& c=\text { concentration of any component, } \\
& D=\text { dispersion coefficient, } \\
& \bar{v}=\text { velocity vector } \\
& t=\text { time, and }
\end{aligned}
$$$$
S=\text { source term for component within differential element. }
$$

When flow in a cylindrical pipe is considered for the case where radial concentration gradients can be neglected and where an infinitesimal quantity of tracer is injected into the pipe, this equation can be simplified to: 
$D \frac{\partial^{2} c}{\partial z^{2}}-\dot{v} \frac{\partial c}{\partial z}-\frac{\partial c}{\partial t}+\stackrel{s}{S}=0$

where $v$ is the velocity distribution across the pipe and $z$ is the axial coordinate.

Several levels of simplification of the more general equation are shown by Bischoff and Levenspiel. (6)

Taylor ${ }^{(7,8)}$ treated the mixing of fluid for both the laminar and turbulent flow regimes. It was shown that the diffusional analogy was appropriate for both regimes and that a tracer material initially confined within a plane (pulse injected) is, for many cases, distributed symmetrically and nearly Gaussian about a point in the flowing stream moving at mean speed. For turbulent flow the distribution of the tracer concentration at time, $t$, was given as:

$$
c=A t^{-1 / 2} \exp \left[-\frac{(z-U t)^{2}}{4 D t}\right]
$$

where:

$$
\begin{aligned}
& A=\text { constant depending upon the amount of material injected, and } \\
& U=\text { mean fluid velocity. }
\end{aligned}
$$

Levenspiel and Smith ${ }^{(9)}$ extended Taylor's treatment of dispersion in a test section of a doubly infinite pipe by making Equation 3 dimensionless. They suggested a form for the dispersion intensity ( $D / U d)$ and investigated the dimensionless tracer concentration-time distribution for a large range of values of the mixing number (D/UL), which is the product of the dispersion intensity and the test section diameter-to-length ratio. It was shown that the distribution of tracer as it passes 
a recording point for relatively large values of the mixing number (say greater than 0.01 ) is skewed, but for small values approaches the normal error (Gaussian) curve.
Carberry and Bretton,
Ebach and White,
(11) Houston
(12) and

Robinson ${ }^{(13)}$ considered fluid intermixing during flow through a pipe packed with solids. Due to the tortuous random paths traveled by the fluid in a packed bed where good radial mixing exists, the treatments by these authors justifies use of Equation 2 for the packed-bed section of a. long length of pipe. Although slightly different boundary conditions were used for each treatment, essentially the same solution was obtained by each. This was shown in a numerical analysis by Robinson. (13) For these treatments obtained for a pulse-type tracer input, most solutions utilized Laplace transform techniques and the method of handling piping upstream and downstream of the test section, as suggested by Wehner and Wilhelm. (14)

For the application of a solution to the dispersion equation, the prediction of dispersion intensity is necessary. In an analysis of dispersion during flow in a cylindrical pipe, Taylor obtained relationships for the dispersion coefficient, D. It was shown that when:

$$
\frac{L}{U} \gg \frac{d^{2}}{28.8 D_{v}},
$$

where:

$$
\begin{aligned}
& \mathrm{L}=\text { length of test section pipe, } \\
& \mathrm{d}=\text { diameter of test section pipe, and }
\end{aligned}
$$




$$
D_{\nu}=\text { molecular diffusion coefficient, }
$$

the dispersion coefficient for the laminar flow regime ${ }^{(7)}$ could be expressed by:

$$
D=\frac{d^{2} u^{2}}{192 D}
$$

In Taylor's treatment of the turbulent flow regime, ${ }^{(8)}$ the dispersion coefficient was expressed by:

$$
D=3.57 \sqrt{f} \cup d,
$$

where $f$ is the fanning friction factor. Levenspiel and Smith ${ }^{(9)}$ demonstrated the use of a second-moment analysis for the experimental determination of the dimensionless group, D/UL (also denoted in this work by $\mathrm{P}$ ), which has been termed the mixing number. When the value of this group is small, the dimensionless variance, $\sigma^{2}$, of the tracer concentration-time curve measured over a length, $L$, of a pipe test section for a pulse-type tracer experiment was found to have the following re-. lationship with the mixing number:

$$
\frac{\mathrm{D}}{\mathrm{UL}}=0.5 \sigma^{2}
$$

where the dimensionless variance, $\sigma^{2}$, is the ratio of the dimensioned variance of the tracer concentration-time curve, $\sigma_{t}^{2}$, to the square of the mean residence time, $\mp$. The dispersion intensity, $\frac{D}{U d^{\prime}}$ is then obtained by multiplying Equation 7 by the test section geometric ratio, $\frac{\mathrm{L}}{\mathrm{d}}$.

By writing partial differential dispersion equations for the upstream, downstream, and test sections, using the end section treatment suggested by Wehner 
and Wilhelm, ${ }^{(14)}$ and solving these equations simultaneously by Laplace transform methods, Van der Laan ${ }^{(15)}$ (later corrected by Bischoff ${ }^{(16)}$ ) obtained relationships for tracer dimensionless variance for a number of piping arrangements. These relationships take into account several arrangements for tracer injection and measurement and also the effect of having upstream and downstream sections with different mixing numbers than exist in the test section; however, they do not include flow disturbances that may exist at the test section ends which may cause significant error by neglection.

Aris ${ }^{(17)}$ described a method for experimentally determining the mixing number for a system which removes the necessity of perfect pulse injection. He demonstrated that by expanding the dimensionless variance relationship in terms of the Laplace transform variable and by measuring the concentration distribution at two locations downstream from the point of injection, any arbitrary tracer form could be used. Later Bischoff, $(18,19,5)$ Bischoff and Levenspiel, ${ }^{(6)}$ and Levenspiel ${ }^{(20)}$ utilized the method. Levenspiel's contribution showed that from a knowledge of the mean residence time and the dimensioned variance for each element of a series of mixing regions in a flow system, the overall mean residence time and dimensioned variance for the system are determinable. These relationships are as follows:

$$
(\bar{t})_{\text {overall }}=\stackrel{i}{i} \stackrel{i}{=} \bar{t}_{i} \text {, }
$$

and 


$$
\left(\sigma_{t}^{2}\right)_{\text {overall }}=\stackrel{i}{i}{ }_{i}\left(\sigma_{t}^{2}\right)_{i}
$$

Subsequently, the dimensionless variance and the mixing number (hereafter noted by $P$ ) are:

$$
\left(\sigma^{2}\right)_{\text {overall }}=\frac{\left(\sigma_{t}^{2}\right)_{\text {overall }}}{(\bar{\dagger})_{\text {overall }}^{2}}
$$

and

$$
(P)_{\text {overall }}=0.5\left(\sigma^{2}\right)_{\text {overall }}
$$

Numerous treatments of mixing in a series of ideally mixed tanks have appeared in the literature. In a review of these articles, ${ }^{(3)}$ it was shown that by simultaneously solving a set of linear, first order, ordinary, material balance, differential equations for each of a series of tanks, the concentration distribution for a pulse input is readily obtained. The balance for the first and the ith tanks are:

$$
C_{0} V \delta(t)-q C_{1}=V \frac{d C_{1}}{d t}
$$

and

$$
q C_{i-1}-q C_{i}=V \frac{d C_{i}}{d t}
$$

where:

$$
\begin{aligned}
C_{0}= & \text { concentration of tracer if mixed homogeneously throughout the } \\
& \text { tank system, }
\end{aligned}
$$


$V=$ volume of each of the ideally mixed tanks,

$\delta(t)=$ delta function of time which equals 0 for $t \neq 0$ and 1 for $t=0$,

$q=$ volumetric flow rate between ideally mixed tanks, and

$t=$ time.

The solution of these equations, as given by Levenspiel, is obtained by Laplace transform techniques, made dimensionless for simplicity and is for the Nth tank of a series:

$$
C_{N}=\frac{N^{N}}{(N-1) !} \theta^{N-1} \exp (-N \theta)
$$

where:

$$
\begin{aligned}
C_{N} & =\text { dimensionless concentration of Nth tank, } \\
\theta & =\text { dimensionless time, and } \\
N & =\text { tank number in the series of tanks. }
\end{aligned}
$$

In addition, it was shown for this model that the dimensionless mean and dimensionless variance are given respectively by:

$$
\mu=1,
$$

and

$$
\sigma^{2}=\frac{1}{N}
$$

In a treatment of longitudinal mixing in a packed bed, Aris and Amundson ${ }^{(21)}$ discussed the probability distribution functions for both models. They demonstrated that a limiting condition of near equivalence exists when: (1) the number of 
equivalent tanks in series becomes large, and (2) the measurement point for the dispersion model is far downstream from the point of tracer injection. The limiting probability distribution approached by both models is the Gaussian distribution. Levenspiel ${ }^{(20)}$ suggested that the dimensionless mean and dimensionless variance of these models can be used to test equivalence. Based on this test, at least ten. tanks $(N=10)$ in series or a mixing number of less than 0.05 is required for approximate equality between the models. 
CHAPTER III

\section{THEORETICAL THREATMENT}

As reflected by a survey of the published literature, only the intermixing of fluids during a single pass through a section of pipe or a piece of process equipment has been considered. A product of one article, for example, written by Levenspiel, ${ }^{(22)}$ was to predict the region of contamination that would exist when two distinct fluids are pumped successively through a common pipeline. Such a treatment finds many applications in the petroleum industry, where the contaminated fluid located near the interface must be removed prior to storage of an effluent stream in product tankage.

Although much of the mixing analysis that has been developed for singlepass mixing can be used in recirculation mixing, the problems are quite different. A solution of the governing differential equation(s) will have significantly different boundary conditions to account for the transport around a loop as compared with the transport through a long straight pipe. Further, the primary objective in a loop-mixing analysis is to predict the time required to mix the contents of a loop to some definition of homogeneity for some given set of conditions. In these respects, the nature of these mixing problems is different.

The necessary relationships for treating the loop-mixing problem are:

1. an expression giving the transient concentration at some fixed point in the loop as a function of the recirculation rate and the components of the tank 
loop (e.g., tank length, tank diameter, loop piping length(s), loop piping diameter(s), and pump volume);

2. expressions for determining a mixing parameter (e.g., mixing number);

and

3. an expression defining the desired end mixed condition which gives the greatest concentration difference acceptable in the loop after mixing.

A prerequisite for an application of the equations describing mixing in a tank loop system is the selection of an appropriate value for the mixing number. As shown by Levenspiel $(20)$ and by Bischoff, $(18,19)$ the dimensioned mean residence time and variance of tracer concentration distribution for each component volume of a flow system can be used to find the overall mean residence time and the overall variance for a system. In the system under study, this treatment cannot be done because dispersion intensity data are only reported in the literature for straight pipe and are not available for pipe fittings or centrifugal pumps. For a first approximation to the mixing number for a tank loop system, all piping was treated by the dispersion model using dispersion intensity data for straight pipe and the pump was treated as an ideally mixed tank.

Because the initial condition of concentration distribution throughout the loop affects the mixing time, a specification of this initial condition must be made. It is obvious that if a given quantity of concentrated solute were evenly distributed throughout the loop but not mixed radially, the tank loop contents will be quickly mixed by turbulent eddies when turbulent flow is achieved. If the same quantity 
of solute were located within a cross-sectional plane at some axial location within the tank, homogeneity can be achieved only after the solute is axially redistributed. This second case requires a greater mixing time than the former for tanks with large length-to-diameter ratios. Since the latter case represents an initial condition that takes the greatest time for solute redistribution than any other case, a theoretical treatment based on this case predicts the maximum value of the mixing time. Experimentally, this condition would require that the solute be injected in a pulse at a specified axial location and conform to the mathematical treatment chosen in this study in an infinitesimal time increment.

For tank loop systems where the degree of mixing and/or the volume associated with the loop piping components can be combined with those of the tank .or possibly neglected, a differential material balance equation identical to those suggested for single-pass dispersion mixing can be applied. As could be shown by an application of Equations 8 (Page 8), 9, and 11 (Page 9), along with a correlation between dispersion intensity and Reynolds number, the dispersive mixing in loop piping of relatively small diameter is often negligible. If, for example, a system mixes in full turbulent flow, where the variables are given in consistent uni tș:

1. the dispersion intensity for the tank, $\frac{D}{U d}$, approximately equals the dispersion intensity for the loop piping (see Figure 1),

2. the tank diameter is four times the loop piping diameter, $d$,

3. the tank length is $3 / 4$ the loop piping length, $L$, and 


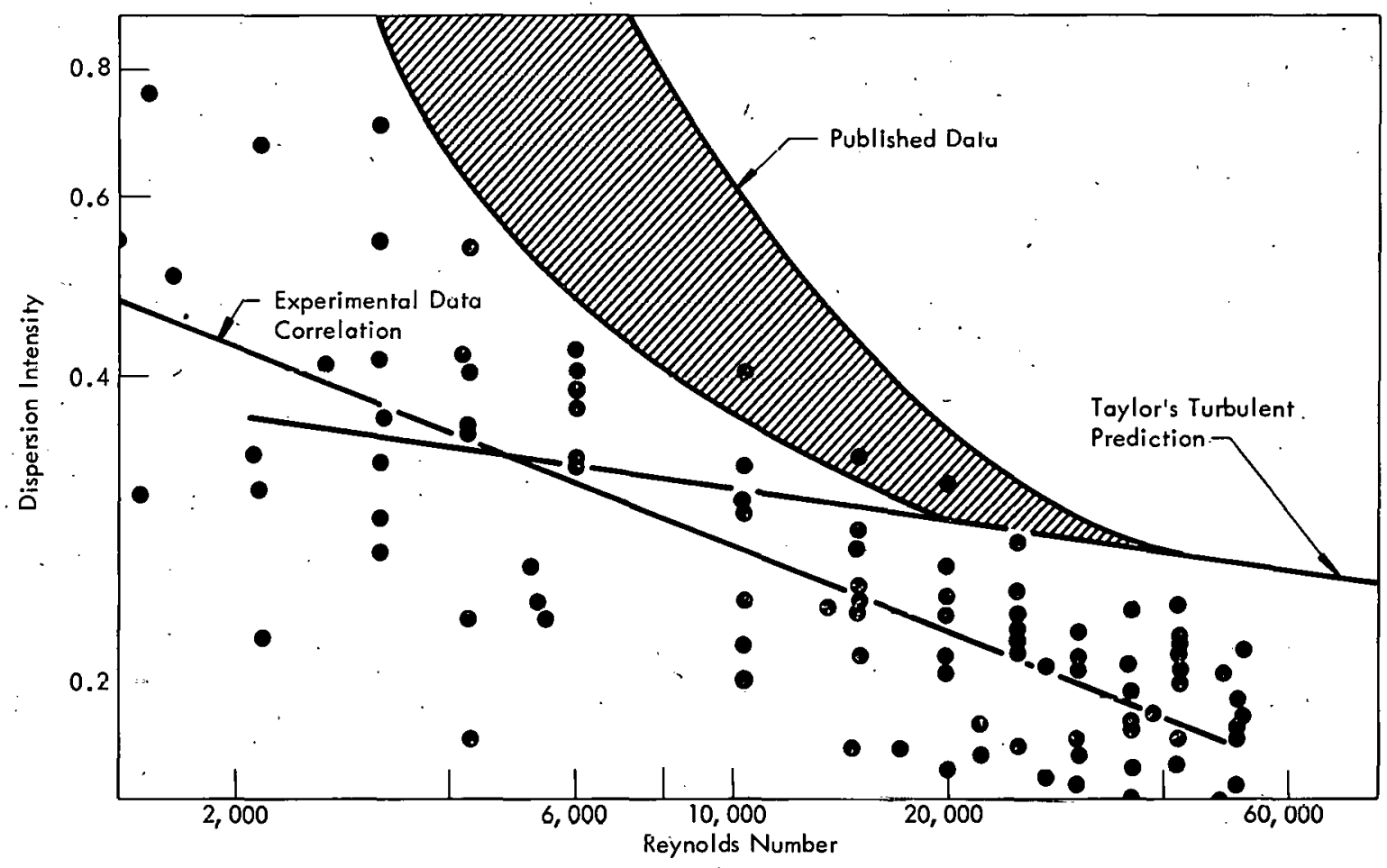

FIGURE 1

EXPERIMENTAL DISPERSION IN TENSITY-REYNOLDS NUMBER CORRELATION WITH COMPARISON TO TAYLOR'S PREDICTION AND PUBLISHED DATA 
4. the system recirculation rate is $Q$.

A tabulation of the steps in computing the mixing number for this loop system is as follows:$$
\frac{\text { Tank }}{\frac{3 \pi d^{2} L}{Q}}
$$$$
\frac{\text { Loop }}{\frac{\pi d^{2} L}{4 Q}}
$$$$
\text { System }
$$
Mean Residence Time
$\frac{\pi d^{2} L}{4 Q}$
$\left(\frac{D}{U L}\right)$
Dimensioned Variance
$48\left(\frac{\pi d^{2} L}{Q}\right)^{2}\left(\frac{D}{U L}\right) \frac{1}{16}\left(\frac{\pi d^{2} L}{Q}\right)^{2}\left(\frac{D}{U L}\right)$
$48.06\left(\frac{\pi d^{2} L}{Q}\right)^{2}\left(\frac{D}{U L}\right)$
Mixing Number

$$
2.667\left(\frac{D}{U L}\right)
$$
$\left(\frac{D}{U L}\right)$
$2.275\left(\frac{\mathrm{D}}{\mathrm{UL}}\right)$

If the dispersive mixing in the loop piping is neglected (note small contribution to the system dimensioned variance), the mixing number can be approximated by using the tank dimensioned variance and the system mean residence time. Thus, an approximated mixing number is $2.272 \frac{\mathrm{D}}{\mathrm{UL}}$ which is off by less than $1 \%$ from the actual system mixing number.

Using the mathematics of the Dirac delta function for handling the pulse injection of tracer and writing the equation in dimensionless form, as described by Bischoff, ${ }^{(5)}$.. the following equation results:

$$
P \frac{\partial^{2} C}{\partial X^{2}}-\frac{\partial C}{\partial X}-\frac{\partial C}{\partial \theta}+\delta(X) \delta(\theta)=0,
$$

where: 
$C=$ dimensionless tracer concentration; defined by the ratio of an axial and time-dependent concentration to the steadystate concentration,

$X=$ dimensionless axial position ranging in value from 0 to 1 ; defined by the ratio of the axial position variable, $Z$, measured from the tank entrance to the equivalent tank length,

$\theta=$ dimensionless time; defined by the ratio of the product of superficial stream velocity and real time to the equivalent tank length,

$P=$ mixing number obtained from the use of Equations $8,9,10$, and 11 , Pages 8 and 9 , and

$\delta(X) \delta(\theta)=$ product of Dirac delta functions of position and of time for mathematically describing the position and time of the tracer injection; equal to 1 at the tank entrance $(X=0)$ and instant of injection $(\theta=0)$, and equal to 0 for all other combinational values of axial positions and time.

Boundary conditions that must be satisfied for the loop problem are:

1. $C(X, 0)=0$, for all $X$,

2. $C(0, \theta)=C(1, \theta)$, and

3. $C(0, \theta)-\left.p \frac{d[C(X, \theta)]}{d X}\right|_{X=0}=C(1, \theta)-\left.P \frac{d[C(X, \theta)]}{d X}\right|_{X=1}$. 
These conditions physically represent the system by stating respectively: (1) that the initial tracer concentration throughout the tank is zero; (2) that the concentration at the tank inlet is equal to the concentration at the tank outlet; and (3) that the transport of tracer by dispersion and convection across the tank loop outlet boundary is equal to the transport by these means across the tank inlet boundary. It is assumed for Conditions 2 and 3 that no mixing occurs in the loop piping or in the pump.

This set of equations $(17,18,19$, and 20 , Pages 16 and 17) is difficult to solve. An attempt was made to obtain a solution by Laplace transform techniques, but the inverse transforms for the solution could not be found. As a consequence, a calculational technique was developed for predicting mixing in a long straight pipe during recirculation by calculating dispersion in a long straight pipe and using superposition.

Levenspiel and Smith ${ }^{(9)}$. showed that the distribution of tracer concentration injected in a pulse at the entrance to a test section in an infinitely long pipe could be described by:

$$
C=\frac{1}{\sqrt{4 \pi \mathrm{P} \theta}} \exp \left[-\frac{(1-\theta)^{2}}{4 \mathrm{P} \theta}\right]
$$

If an appropriately selected mixing number is substituted into this' equation, the concentration distribution as a function of the dimensionless time for the first pass of a pulse-injected tracer is determinable. 
For the application of superposition, Equation 21 can be generalized with respect to distances. For a fluid at rest:

$$
\frac{\partial c}{\partial t}=D \frac{\partial^{2} c}{\partial z^{2}}
$$

a solution as given by Carslaw ${ }^{(23)}$ exists:

$$
c=\frac{V_{0} L}{2 V \sqrt{\pi D t}} \exp \left[\frac{-z^{2}}{4 D t}\right],
$$

where:

$$
\begin{aligned}
V_{0}= & \text { volume of solution within which injected tracer would have unit } \\
& \text { concentration, and } \\
V= & \text { volume of test section where dispersion is considered. }
\end{aligned}
$$

The relationship for the dispersion of a pulse of tracer about a point not at rest but moving through a pipe at a mean velocity, $U$, immediately follows:

$$
c=\frac{V_{o} L}{2 V \sqrt{\pi D t}} \exp \left[\frac{-(z-U t)}{4 D t}\right] \text {. }
$$

This equation is made dimensionless by the following defined terms:

$$
\begin{aligned}
& P=\frac{D}{U L}: \text { mlxlng riumber, } \\
& \theta=\frac{Q t}{V}: \text { dimensionless time, } \\
& X=\frac{Z}{L}: \text { dimensionless axial tank length, and } \\
& C=\frac{c V}{V_{0}}: \text { dimensionless concentration. }
\end{aligned}
$$


Upon substitution into Equation 24, a dimensionless concentration-time relationship with a single parameter, mixing number, results:

$$
C=\frac{1}{\sqrt{4 \pi P \theta}} \exp \left[\frac{-(X-\theta)^{2}}{4 P \theta}\right] \text {. }
$$

When $X=1$, the equation of Levenspiel and Smith is checked; however, positive integral values of dimensionless axial length greater than unity also have significance. For example, when $X=\eta$, the mixing in a piping section with volume, $\eta V$; length, $\eta L_{;}$and mixing number, $\frac{D}{U_{\eta} L^{\prime}}$ is directly predictable. The set of equations for which $\eta=1,2,3, \ldots, \xi$ gives the dimensionless concentration-time relationship for a pulse of tracer that is to be measured at an axial position downstream from the injection point of $\eta \mathrm{L}$. For the problem of mixing in a loop tankage system, it gives the spread of tracer that would be found for the $\eta$ th pass of tracer moving at a mean velocity around the loop if tracer were diluted into a volume, $\eta \vee$. That is, it neglects the intermixing of the tails of the spreading Gaussian function after the tracer has spread over an axial length greater than $X=1$.

To account for this intermixing of tracer, a sum of the dimensionless concentration for each equivalent pass is made in the range of dimensionless time, $\theta$, of interest. Then the concentration-time relationship measured at the tank outlet can be expressed as:

$$
C=\sum_{i} \frac{1}{\sqrt{4 \pi P \theta}} \exp \left[-\frac{(i-\theta)^{2}}{4 P \theta}\right]
$$


This concentration relationship follows naturally for the equivalent case of dispersive intermixing for steady periodic concentration in an infinitely long pipeline when tracer is periodically injected. For this case, the tracer must be injected at a time increment equal to the mean residence time for each section of length $X=1$. The time increment, $\tau$, then would be:

$$
\tau=\frac{V}{U}
$$

Each element of tracer injected at these time increments would disperse according to Equation 25 as it moves through the infinitely long pipeline, and the concentration at any point can be determined by superposition.

A desired end-mixed condition describing the greatest tracer concentration difference in a tank loop system must be specified as a test criterion for the mixing time calculations. By a comparison of the peak tracer concentration for each pass with the ultimate (steady state) concentration after a large mixing period, an easily utilized end mixing condition testing the degree of inhomogeneity can be used. Such a test for mixing-time determination will associate mixing time for a given tank loop system and recirculation rate with the time lapse between, pulse injection and the first peak concentration value which meets the test criteria. Based on these conditions, the following mixing-time test can be used:

$$
\gamma \geq \frac{c_{\infty}}{C_{p}},
$$

where: 


$$
\begin{aligned}
& C_{P}=\text { maximum dimensionless peak concentration, } \\
& C_{\infty}=\text { ultimate steady-state concentration, and } \\
& \gamma=\text { parameter defining the desired end-mixed condition. }
\end{aligned}
$$

From an inspection of Equations 26 and 28, it is clear that the dimensionless mixing time is dependent solely upon the mixing number, $P$, and the desired. end condition parameter, $\gamma$. By selecting a range of values for these parameters, their relationship with the dimensionless mixing time, $T$, can be studied from numerical calculations. Since the solution of these equations is well suited to high-speed digital computers, a computer program was written for use at the Oak Ridge Gaseous Diffusion Plant Central Data Processing Facility and was run on an IBM 7090 digital computer.

Since Levenspiel's compiled dispersion intensity data ${ }^{(24)}$ for turbulent flow ranges between 0.2 and 1.0 , and the length-to-diameter ratio for solution storage tankage in nuclear fuel plants generally range between 20 and 150 , a range for the mixing number between 0.001 and 0.1 was used. Values for $\gamma$ which reflect near homogeneity (i.e., $Y$ approaching 1.0) were selected for the computations.

In order to accurately locate the concentration maxima which are displaced from the integral positive values of dimensionless time, $\theta$, due to the skewness of the concentration-time function at relatively large mixing numbers, the computer program used the property of time location for a maximum: 
$\frac{d}{d \theta} C(\theta, i)=0$

For Equation 26, the time derivative is:

$$
\frac{d}{d \theta} C(\theta, i)=\sum_{i}\left[i^{2}-2 P \theta-\theta^{2}\right] \exp \left[-\frac{(i-\theta)^{2}}{4 P \theta}\right] \text {. }
$$

Based on Equations 29. and 30, the time location of the first concentration maximum can be found by algebra (NOTE: $i=1$ ), or:

$$
\theta=-P+\sqrt{P^{2}+1}
$$

A test of this concentration maximum to the steady-state concentration is made by Equation 28. For a tank loop system where the tank has a reasonably large length-to-diameter ratio, the initial test will fail. Subsequent concentration maximum time locations are obtained by estimating the peak, as located one dimensionless time unit further along the time scale, and using an iterative method of locating a more accurate value for the peak time. A test of the end-mixed criterion is repeated. The process of estimating the peak time location and using the end-mixed criterion is repeated until the criterion is met. The mixing time then has the time value for the peak maximum which was accepted.

In the course of solving Equations 26 and 28 for mixing time, it was found that the value of $j$ must be at least 200 in order to make the contributions of subsequent pulse maxima, beyond that corresponding to the mixing time, negligible. 
Mixing-time calculations were performed for seven levels of end-mixed condition between 0.90 to 0.9995 and for nine levels of mixing numbers ranging between 0.001 to 0.1 . A listing of these mixing times is given in Table 1. For mixing numbers less than about 0.7 , a linear relationship exists between the logarithm of the mixing number and the logarithm of the dimensionless mixing time for any of the end-mixed conditions considered. These calculated points scattered slightly because mixing time is based on an integral number of recirculation passes. As a consequence, a linear fit of those data sets was made to an equation of the form:

$$
\log T=A-B \log P,
$$

where:

$T=$ dimensionless mixing time, and

$A$ and $B$ are least-squares fit constants.

The data are graphically represented in Figure 2 by these linear fits. A listing of the fit constants, their standard error, and an estimate of the variance for each fit are given in Table II. An excellent fit of these data was obtained as indicated by the estimate of variance for each fit.

By using the linear fit of mixing number and dimensionless mixing time, it is possible to predict the mixing time for any tank loop system by the following procedure:

1. calculate the loop system mixing number, P, using Equations 8 (Page 8), 9, 10, and 11 (Page 9) and a correlation between the dispersion intensity and 
TABLE ।

PREDICTED DIMENSIONLESS MIXING TIME AS A FUNCTION OF THE MIXING NUMBER

\begin{tabular}{lrrrrrrrr}
\hline \hline $\begin{array}{c}\text { Mixing } \\
\text { Number }\end{array}$ & \multicolumn{7}{c}{ Dimensionless Mixing Time ${ }^{a}$ at Mixed Conditions of } \\
\cline { 2 - 8 } & 0.900 & 0.950 & 0.990 & 0.995 & 0.998 & 0.999 & 0.9995 \\
\hline 0.001 & 75.9990 & 93.9990 & 134.9990 & 148.9756 & .172 .9990 & 192.9990 & 210.9990 \\
0.002 & 37.9980 & 46.9980 & 67.9980 & 75.9980 & 87.9980 & 96.9980 & 105.9980 \\
0.004 & 18.9960 & 23.9960 & 33.9960 & 37.9960 & 43.9960 & 48.9960 & 52.9960 \\
0.007 & 10.9930 & 13.9930 & 19.9930 & 21.9930 & 24.9930 & 27.9930 & 30.9930 \\
0.01 & 7.9900 & 9.9900 & 13.9900 & 15.9900 & 17.9900 & 19.9900 & 21.9900 \\
0.02 & 3.9801 & 4.9801 & 6.9801 & 7.9801 & 8.9801 & 9.9801 & 10.9801 \\
0.04 & 1.9609 & 2.9609 & 3.9609 & 3.9609 & 4.9609 & 4.9609 & 5.9609 \\
0.07 & 1.9419 & 1.9419 & 1.9419 & 2.9371 & 2.9371 & 2.9371 & 3.9354 \\
0.10 & 1.0417 & 1.0417 & 2.2791 & 2.2791 & 3.7258 & 3.7258 & 3.7258 \\
\hline \hline
\end{tabular}

${ }^{a}$ These mixing times were computed from Equalions 26 and 28 using an IBM 7090 digital computer. 


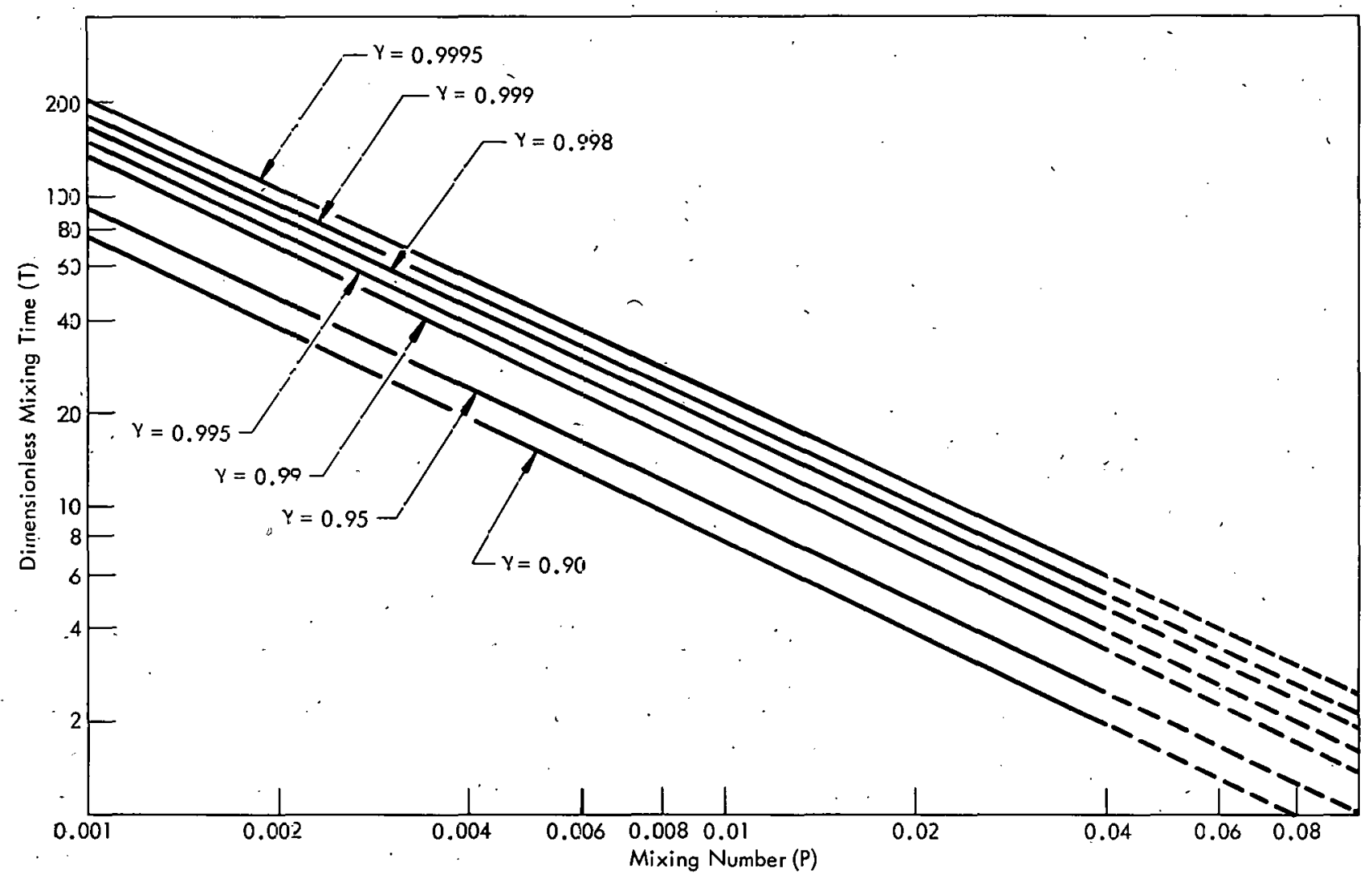

FIGURE 2

LINEAR CORRELATIONS TO PREDICTED DIMENSIONLESS MIXING TIME-MIXING NUMBER DATA FOR SEVEN MIXED CONDITIONS 
TABLE II

CORRELATION COEFFICIENTS AND ERROR ESTIMATES FOR'THE CORRELATIONS - DIMENSIONLESS MIXING TIME MIXING NUMBER

\begin{tabular}{|c|c|c|c|c|c|}
\hline \multirow[b]{2}{*}{$\begin{array}{l}\text { Mixed } \\
\text { Condition }\end{array}$} & \multicolumn{2}{|c|}{ Constant $\mathrm{A}^{\mathrm{a}}$} & \multicolumn{2}{|c|}{ Constant $\mathrm{B}^{\mathrm{a}}$} & \multirow{2}{*}{$\begin{array}{l}\text { Variance of } \\
\text { Estimate } \\
\text { of Fit }\end{array}$} \\
\hline & Valuè & $\begin{array}{l}\text { Standard } \\
\text { Error }\end{array}$ & Value & $\begin{array}{c}\text { Standard } \\
\text { Error }\end{array}$ & \\
\hline 0.900 & 1.0808 & 0.0110 & 0.9865 & 0.0049 & 0.0001 \\
\hline 0.950 & 0.9587 & 0.0094 & 0.9763 & 0.0040 & 0.0001 \\
\hline 0.990 & 0.8292 & 0.0083 & 0.9863 & 0.0034 & 0.0001 \\
\hline 0.995 & 0.7672 & 0.0098 & 0.9810 & 0.0044 & 0.0001 \\
\hline 0.998 & 0.6829 & 0.0220 & 0.9713 & 0.0097 & 0.0002 \\
\hline 0.999 & 0.6857 & 0.0052 & 0.9906 & 0.0023 & 0.0001 \\
\hline 0.9995 & 0.5982 & 0.0167 & 0.9714 & 0.0074 & 0.0001 \\
\hline
\end{tabular}

a Correlation coefficients (Constants A and B) fit data listed in Table I to Equation 32 . 
Reynolds number;

2. for a given end-mixed condition, $Y$, obtain the dimensionless mixing time, T, from Figure 2; and

3. calculate the dimensioned mixing time, ${ }^{t}{ }_{m}$, by the product

$$
r_{m}=T\left(\frac{V}{Q}\right) \text {. }
$$


CHAPTER IV

\section{EXPERIMENTAL FACILITY}

An experimental facility simulating the horizontal, recirculation-mixed, safe tank systems as found in nuclear fuel processing plants was constructed, as. shown in Figure 3. All piping and analytical components were arranged to easily accomodate the changes in the tank lengths (15 feet to 40 feet) considered.

To permit observation of the flow, each 'tank was built of Pyrex pipe: ${ }^{(*)}$

A tank was assembled from four or six-inch-diameter flanged sections of pipe five feet long and ten feet long as needed. Each tank was mounted in a $21 / 2$ by $21 / 2$ by $1 / 4$-inch angle iron framework, inclined about $1 / 5$ inch per foot to facilitate drainage and elevated at least five feet above the floor level. For smooth flow transition at tank ends, flanged, concentric, Pyrex reducers to two-inch pipe were used. Loop piping connecting the tank to the prime mover suction and discharge was fabricated from either $11 / 2$ or 2 -inch Schedule 40 stainless steel pipe. In the discharge piping, a section five feet long was provided for the admission of a tracer solution to the system. This section, which is shown in Figure 4, could be isolated by closing ball valves, at each end, draining, and then filling with tracer from an upper level head tank by manipulating 1/2-inch drain-and-fill lines. A

${ }^{(*)}$ As manufactured from Type 7740 borosilicate glass by the Industrial Products Division of Corning Glass Works. 


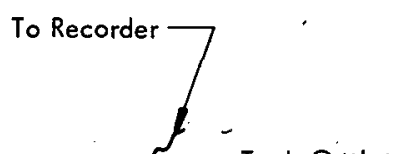
Conductivity Cell

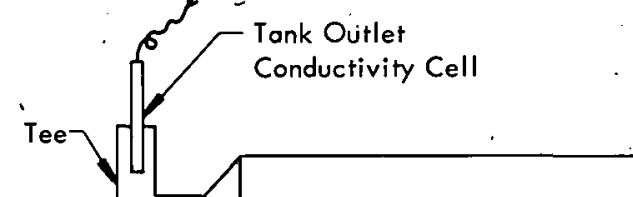

Four or Six-Inch-

Diameter Safe Tank

Tracer

Head Tank
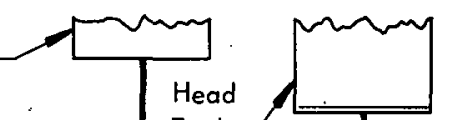

Overflow Line 7

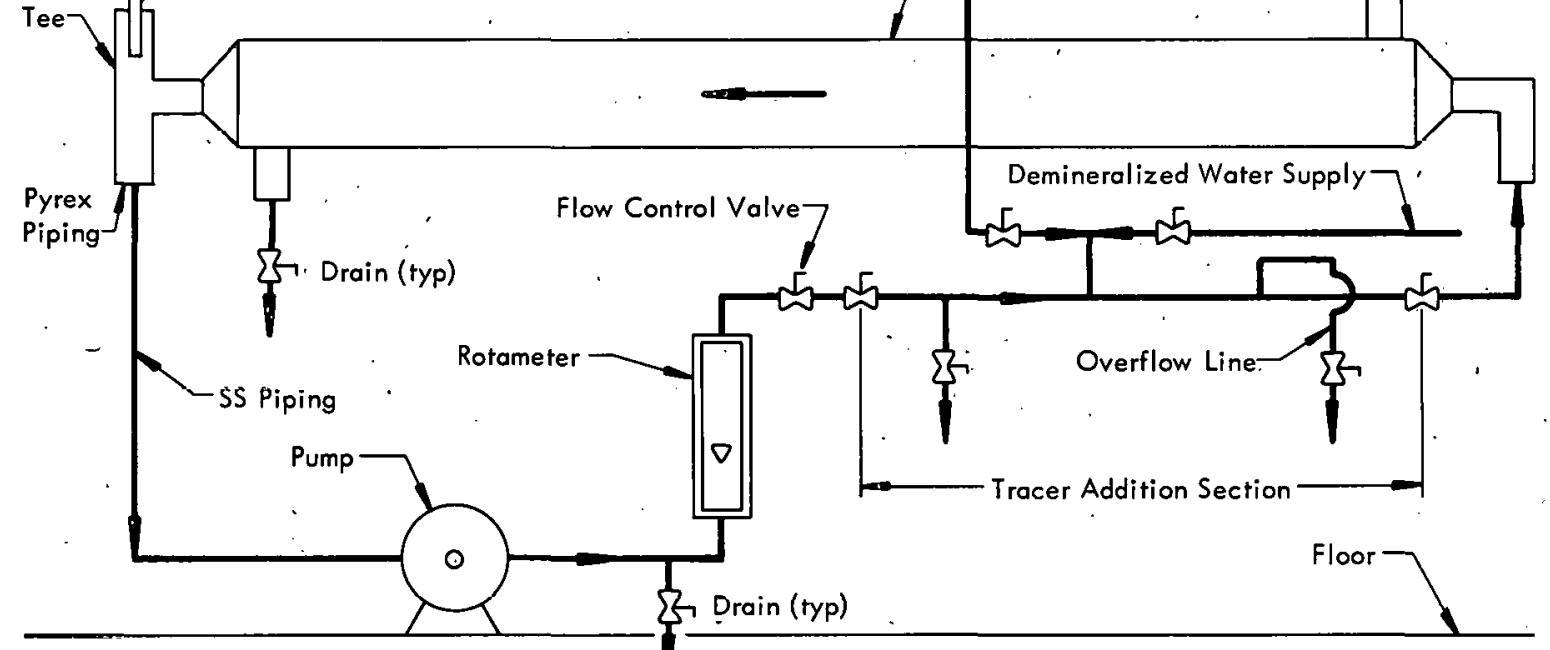

FIGURE 3

REPRESENTATIVE ARRANGEMENT FOR EXPERIMENTAL TANK LOOP SYSTEMS 


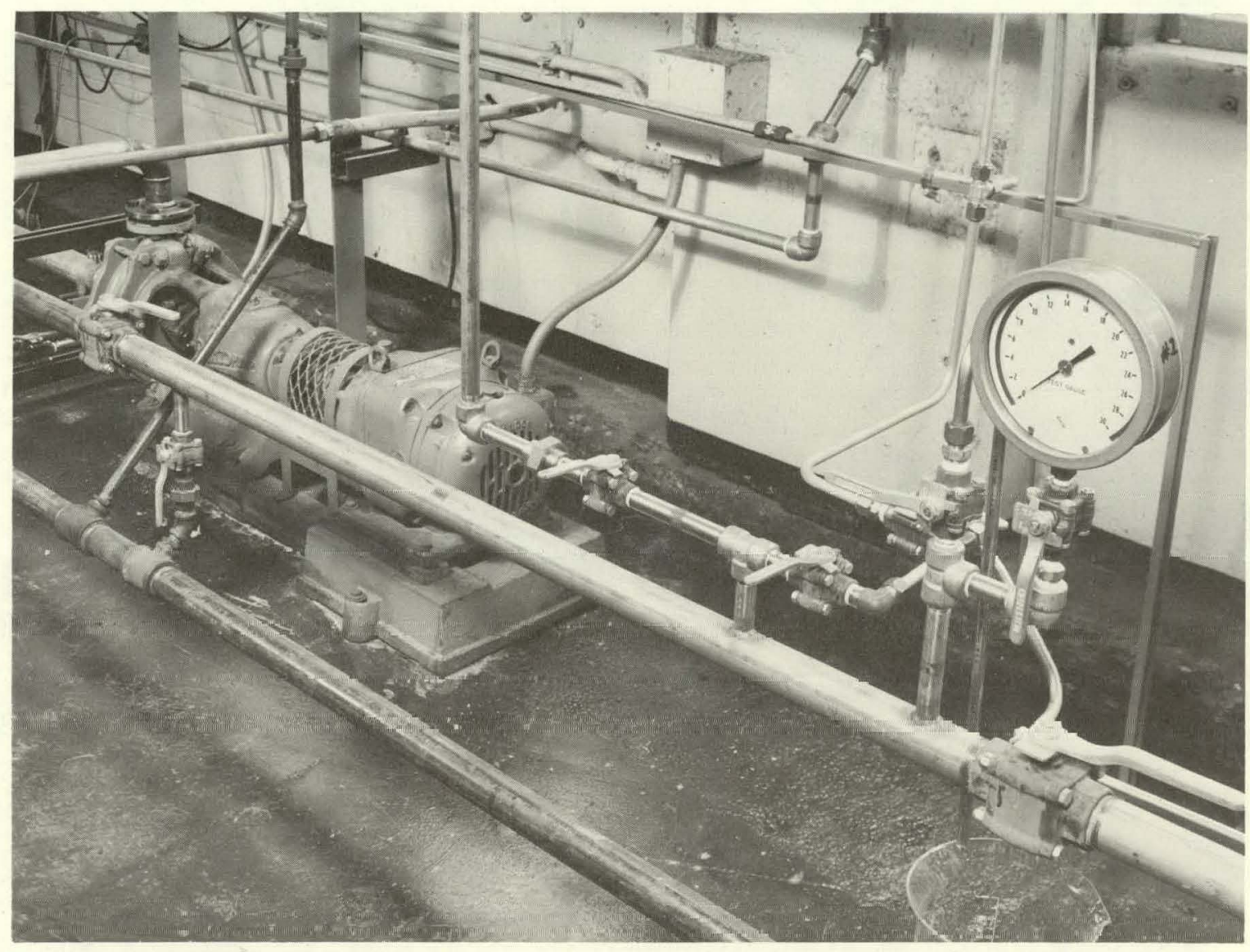

FIGURE 4

TRACER ADDITION PIPING 
1/2-inch-diameter tube connected the safe tank system with a 12-gallon widemouth, Pyrex glass tracer head tank located on the next floor. Demineralized water used as the bulk fluid within a tank system was supplied from a building header to the facility through a connection to the tracer admission section.

To move fluid around the system loop, a centrifugal pump capable of pumping up to 120 gallons per minute at discharge pressures up to about 100 pounds per square inch gage was used. For flow measurement and control, a rotameter was installed downstream from the pump. To extend the range of flow for the rotameter $^{(* *)}$ a light and a heavy rotameter float were used to cover the 1 to 100 gallon-per-minute range. By adjusting a globe valve downstream from the rotameter while observing the rotameter, selected flow-rate settings were possible.

For instantaneous and continuous measurement of tracer concentration, an electrical conductivity cell was mounted at the tank outlet in a flanged, Pyrex, two-inch tee. To perform several special experiments, two al ternate locations were used. These places included a cell mounted in the tank outlet reducer and a cell mounted in the center test section of a tank through a flanged six by six by two-inch Pyrex tee. These cell connections are pictured in Figures 5 through 7. The cells ${ }^{(* *)}$ incorporate measurements of electrical conductivity at the cell

${ }^{(* *)}$ Brooks Instrument Company Model 1110. ${ }^{(* * *)}$ Model CEL-II (SS) x 1-02, manufactured by Industrial Instruments, Inc. 


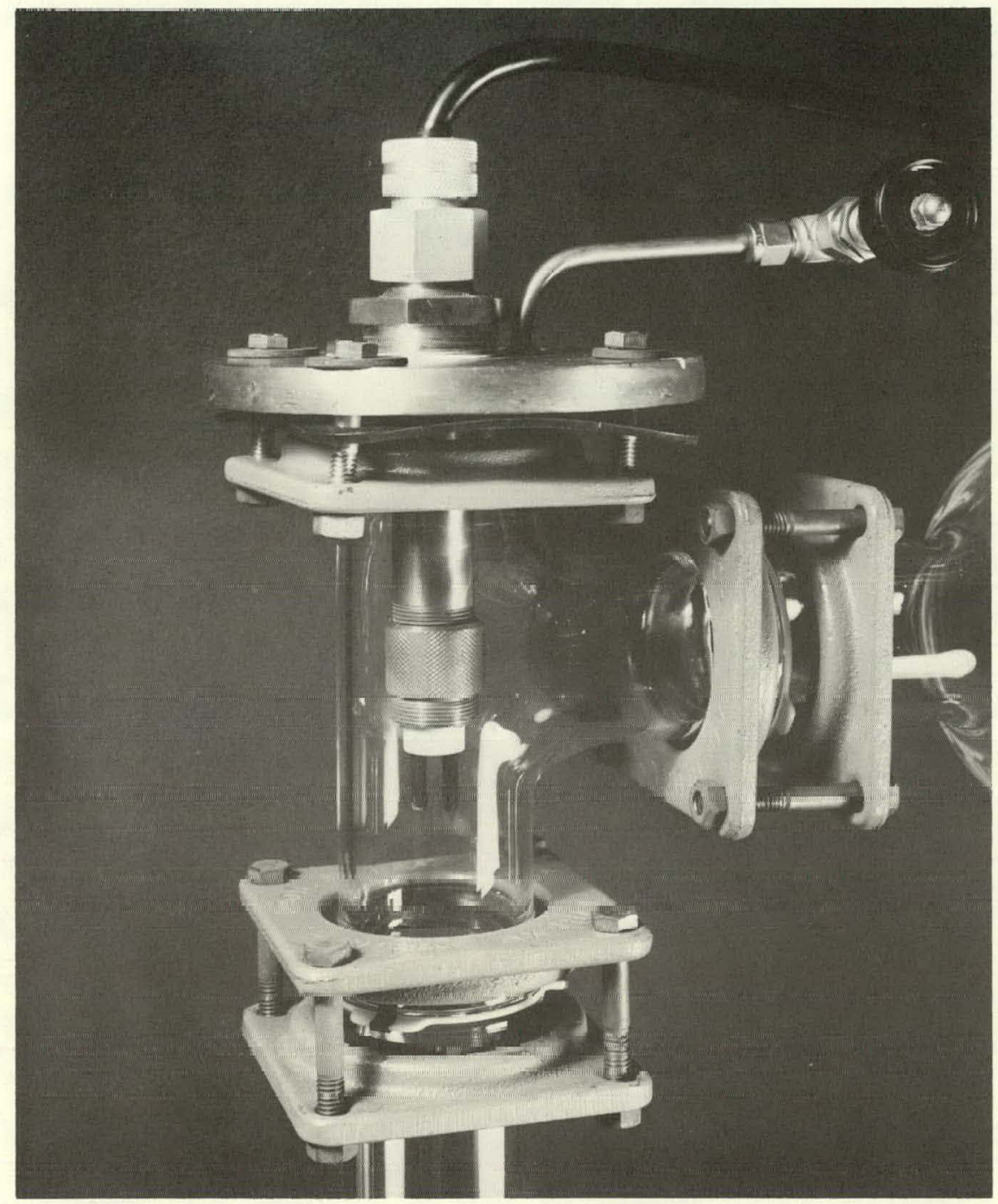

FIGURE 5

MOCKUP OF A CONDUCTIVITY CELL MOUNTED IN A TWO-INCH TEE AT THE TANK OUTLET 


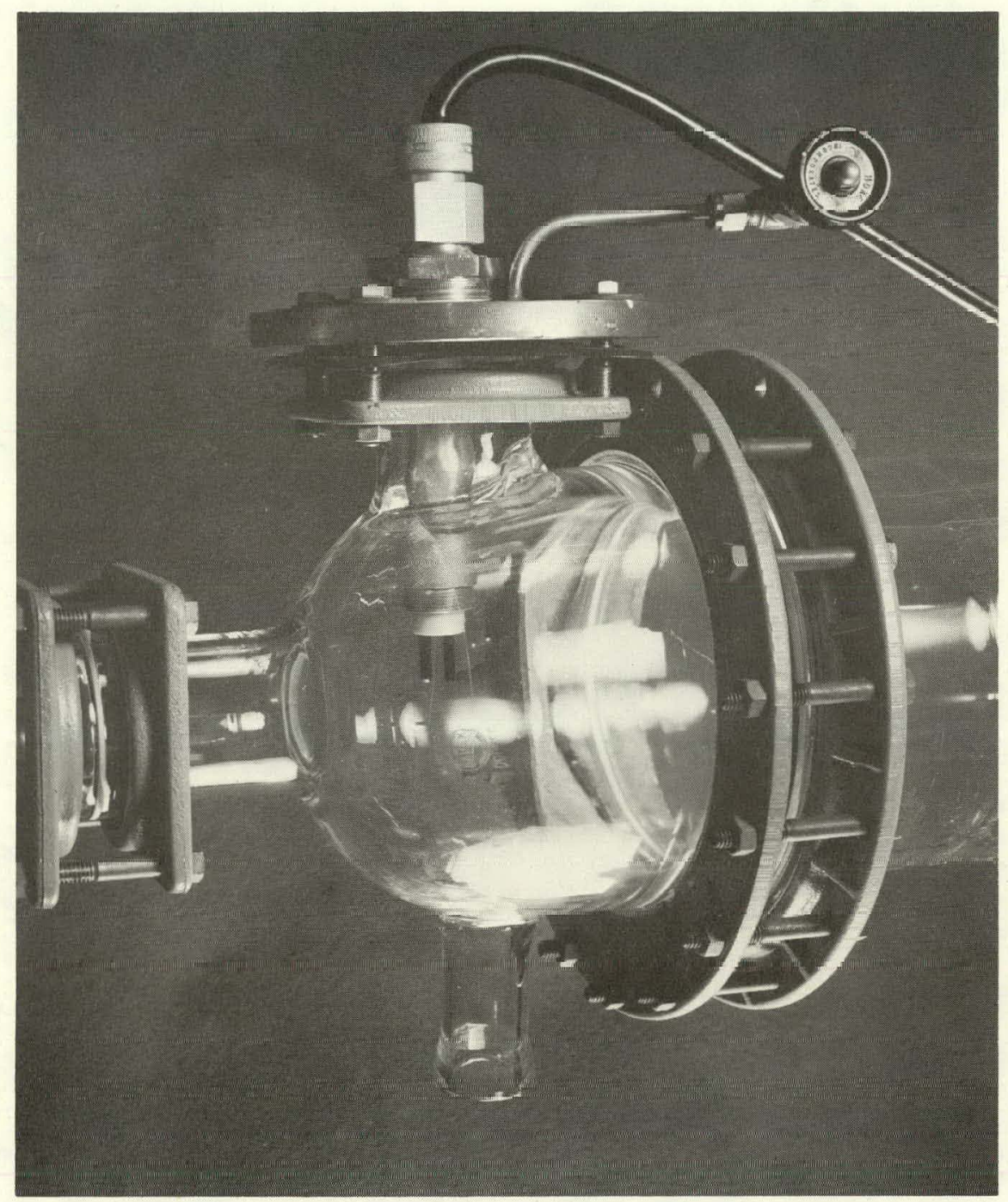

FIGURE 6

MOCKUP OF A CONDUCTIVITY CELL MOUNTED AT THE TANK OUTLET IN A REDUCER 


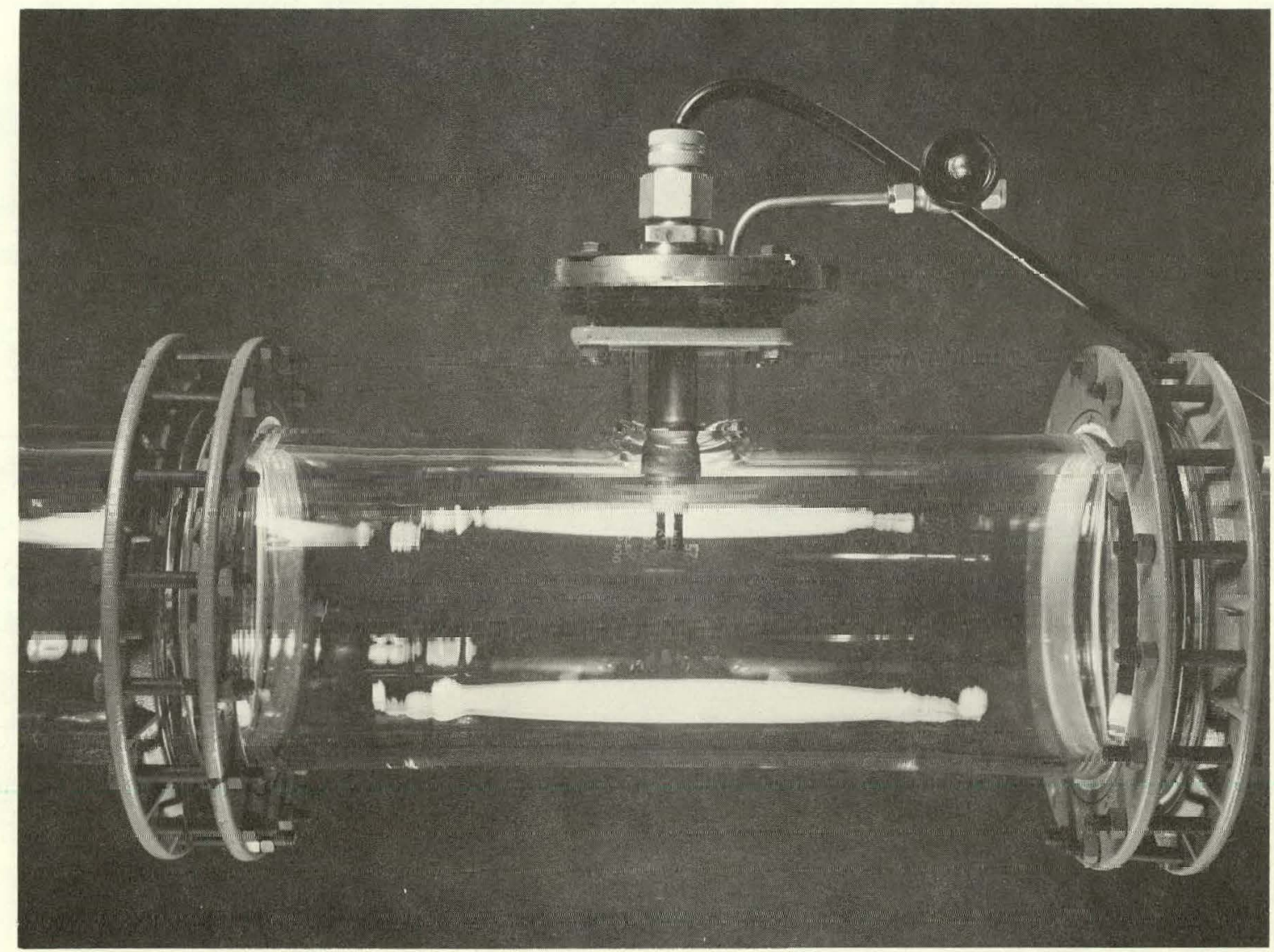

FIGURE 7

MOCKUP OF A CONDUCTIVITY CELL MOUNTED WITHIN A TANK ONTO A SIX BY SIX BY TWO-INCH TEE 
electrodes and compensation of the conductivity measurement at the system temperature to $25^{\circ} \mathrm{C}$. The electrical resistance for the conductivity measurement and for the temperature compensation from the mounted cell were used in two legs of a continuously null balanced AC Wheatstone bridge circuit adapted to an 11 -inch strip chart recorder. ${ }^{(* * *)}$ Adaptation of the measurement circuitry to the $41 / 2$-second full-scale recorder and calibration of the system was performed by Industrial Instruments, Inc. Since the circuitry utilizes resistive impedances, measurement response time was primarily limited by the recorder pen speed. As the maximum slope for any concentration-time measurement was found to be less than $15 \% \mathrm{FS} / \mathrm{sec}$. (full scale per second) and the recorder is capable of a slewing speed of $28.5 \% \mathrm{FS} / \mathrm{sec}$, the recorder was adequate for the collection of mixing data. Further, peak loss for these measurements was measured by Minneapolis Honeywell to be less than about $0.3 \% \mathrm{FS}$.

During the course of the experimental program where different tank diameters and tank lengths were considered, three separate systems were built each with a separate but identical rotameter and conductivity recorder. A view of the experimental facility is presented in Figure 8. A tabulation of piping lengths and volumes, of miscellaneous volumes, and the aggregate system volume for each safe tank system considered is presented in Table III.

${ }^{(* * *)}$ Minneapolis Honeywell. 


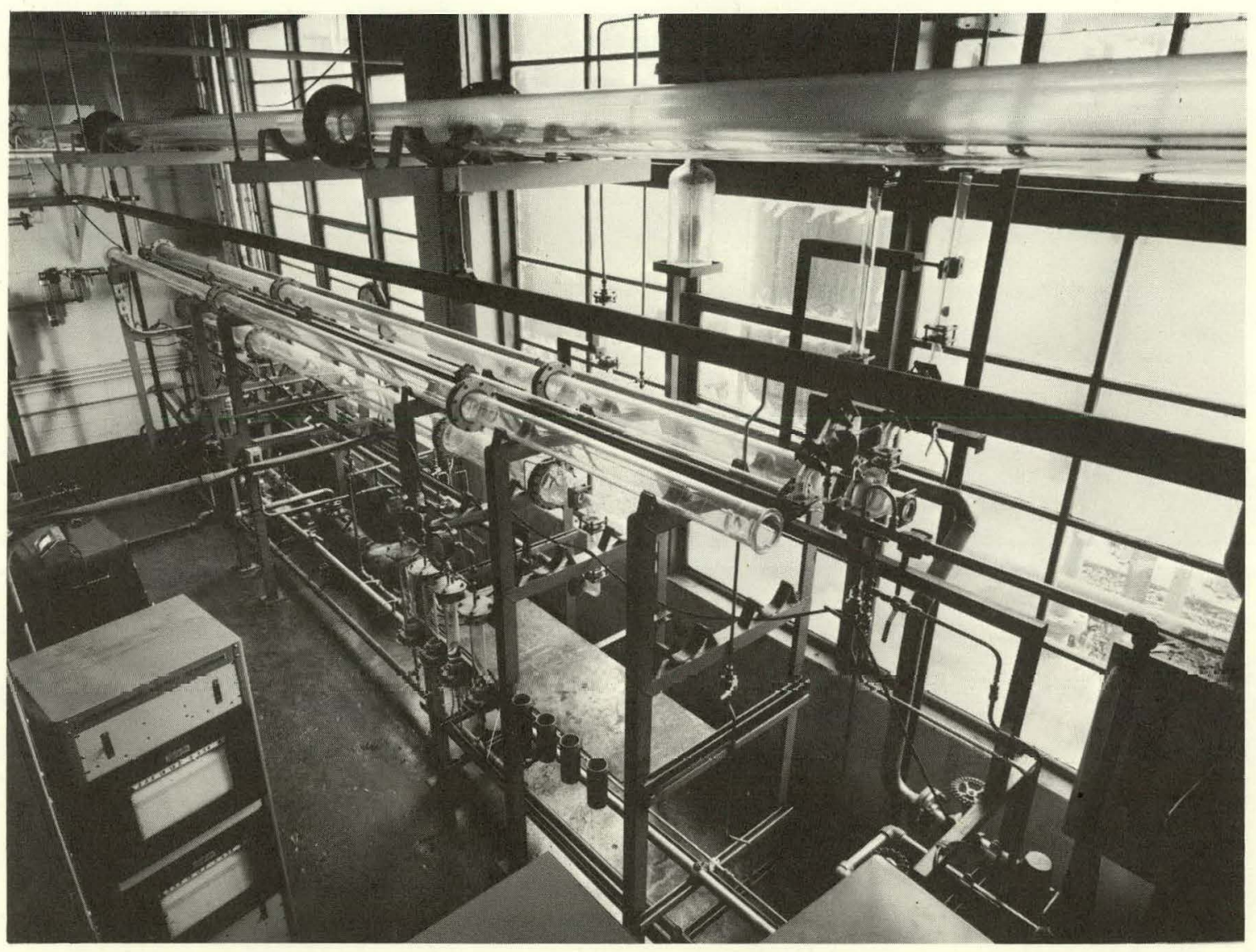

FIGURE 8

THE EXPERIMENTAL FACILITY 
TABLE III

CHAR.ACTERISTIC JPE LENGTHS AND COMPONENT VOLUMES FOR THE TANK LOOP SYSTEMS STUDIED

\begin{tabular}{|c|c|c|c|c|c|c|c|c|c|c|c|}
\hline \multirow[b]{2}{*}{$\begin{array}{l}\text { Series } \\
\text { Number }\end{array}$} & \multirow{2}{*}{$\begin{array}{l}\text { Tank } \\
\text { Diameter } \\
\text { (inches) }\end{array}$} & \multirow{2}{*}{$\begin{array}{l}\text { Tank } \\
\text { Length } \\
\text { (feet). }\end{array}$} & \multirow{2}{*}{$\begin{array}{l}\text { Tank } \\
\text { Fullness } \\
\text { (\%. }\end{array}$} & \multirow{2}{*}{$\begin{array}{l}\text { Tank } \\
\text { Volume } \\
\text { (gallons) }\end{array}$} & \multicolumn{2}{|c|}{ Two-Inch Pipe } & \multicolumn{2}{|c|}{ 1.5-Inch Pipe } & \multirow{2}{*}{$\begin{array}{c}\text { Pump } \\
\text { Volume } \\
\text { (gallons) }\end{array}$} & \multirow{2}{*}{$\begin{array}{c}\text { Miscellaneous System } \\
\text { Volumes } \\
\text { (gallons) }\end{array}$} & \multirow{2}{*}{$\begin{array}{l}\text { Total System } \\
\text { Volume } \\
\text { (gallons) }\end{array}$} \\
\hline & & & & & $\begin{array}{l}\text { Length } \\
\text { (feet) }\end{array}$ & $\begin{array}{c}\text { Volume } \\
\text { (gallons) }\end{array}$ & $\begin{array}{l}\text { Length } \\
\text { (feet) }\end{array}$ & $\begin{array}{r}\text { Volume } \\
\text { (gallons) }\end{array}$ & & & \\
\hline 1 & 4 & 15 & 100.0 & 9.7 & 15.6 & 2.7 & 22.1 & 2.33 & 0.22 & 1.16 & 16.21. \\
\hline 3 & 4 & 25 & $10 \mathrm{C} .0$ & 16.3 & 16.7 & 2.9 & 22.1 & 2.33 & 0.22 & 1.08 & 22.85 \\
\hline 6 & 6 & 15 & 100.0 & 22.0 & 7.9 & 1.3 & 20.4 & 2.16 & 0.34 & 1.81 & 27.73 \\
\hline 8 & 6 & 20 & 100.0 & 29.3 & 16.7 & 2.9 & 14.6 & 1.54 & 0.34 & 1.81 & 35.97 \\
\hline 11 & 6 & 25 & 100.0 & 36.7 & 16.7 & 2.9 & 20.4 & 2.16 & 0.34 & 1.81 & 43.93 \\
\hline .16 & 6 & 20 & 100.0 & 29.3 & 16.7 & 2.9 & 14.6 & 1.54 & 0.34 & 1.81 & 35.97 \\
\hline 17 & 6 & 20 & 103.0 & 29.3 & 16.7 & 2.9 & 14.6 & 1.54 & 0.34 & 1.81 & 35.97 \\
\hline 18 & 6 & 26 & 100.0 & 38.1 & 16.7 & 2.9 & 20.6 & 2.18 & 0.34 & 1.81 & 45.42 \\
\hline 19 & 6 & 26 & 100.0 & 38.1 & 16.7 & 2.9 & 20.6 & 2.18 & 0.34 & 1.81 & 45.42 \\
\hline 24 & 6 & 40 & 100.0 & 58.7 & 66.3 & 11.5 & 6.3 & 0.67 & 0.22 & 2.51 & 73.72 \\
\hline 26 & 6 & 40 & 100.0 & 58.7 & 66.3 & 11.5 & 6.3 & 0.67 & 0.22 & 2.51 & 73.72 \\
\hline
\end{tabular}

${ }^{a}$ The listed tank volumes do iot inclede tank reducers. The reducers were included in the miscellaneous system volumes. 


\section{CHAPTER $\vee$}

\section{EXPERIMENTAL PROCEDURE}

At the outset, all analytical components of the experimental facility were calibrated and fit to an equation to facilitate computer methods. Rotameters. for recirculation rate measurement were calibrated by the Physical and Electrical Standards Laboratory of the $\mathrm{Y}-12$ Plant by collecting the throughput stream for a measured time. These data were collected over the full range of flow for each rotameter-float combination and fit to a polynominal curve of the form:

$$
Q=A+B R+E R^{2}+F R^{3},
$$

where:

$$
\begin{aligned}
& Q=\text { flow rate (gallons per minute), } \\
& R=\text { scale reading (millimeters), and }
\end{aligned}
$$

$A, B, E$, and $F=$ constants of the least-squares data fit.

For these fits, the greatest standard deviation of fit was 0.305 gallon per minute for the 10 to 100 g.p.m. ranges, and 0.101 g.p.m. for the 1 to 10 g.p.m. ranges. Conductivity measuring equipment was calibrated by measuring at room temperature the conductivity of aqueous sodium chloride solutions made from measured weights of dried, reagent-grade sodium chloride and demineralized water. As the relationship between conductivity and concentration for dilute solutions is linear when plotted on full logarithmic paper, a fit of these calibration data was made to 
an equation of the form:

$$
\ln K=A+B \ln c \text {, }
$$

where:

$$
\begin{aligned}
& K=\text { solution conductivity (micromhos/cm.), } \\
& c=\text { salt concentration (p.p.m. NaCl by weight), and }
\end{aligned}
$$

$A$ and $B=$ constants of the least-squares data fit.

The greatest standard deviation of fit for the three conductivity measuring units was 0.0578 (logarithmic units). These data were found to compare well with the published literature data. $(25,26)$

A supply of highly concentrated tracer solution was made by adding reagent-grade sodium chloride to two gallons of demineralized water (which has a total salt content equivalent to less than $1 / 2$ p.p.m. sodium chloride). To this solution with a salt concentration of about $20 \%$ by weight, a small quantity of an organic dye, fluorescein disodium salt, ${ }^{(*)}$ was added to assist in visually following the tracer-during flow through the system's Pyrex glass tank. The contribution of the dye to the saline tracer conductivity was found to be negligibly small. A dilute tracer solution for use in the experimentation was made by adding about $300^{\circ}$ milliliters of the concentrated salt solution to about 12 gallons of demineralized water in the tracer head tank and homogenizing these by air sparging. In this

${ }^{*}$ Designated as Chemical 735 by the Distillation Products Division of Eastman Kodak Company. 
way, a tracer solution with a concentration of several thousand parts per million by weight was prepared. 
CHAPTER VI

\section{ANALYSIS AND DISCUSSION OF RESULTS}

Dispersion Intensity Data

The relationship between dispersion intensity and Reynolds number was experimentally studied for six horizontal-tank loop system arrangements by using an approximation to pulse tracer injection. It was found that the logarithms of these data, for the first pass through these tank systems, could be fit by a linear equation over the full range of the Reynolds numbers investigated which extended from the laminar flow region (Reynolds numbers less than 2,100) well into the turbulent region. Although a nearly linear relationship between the logarithm of the dispersion intensity and the logarithm of the Reynolds number was expected for the turbulent region, as might be shown for straight smooth pipe by using Taylor's prediction (Equation 6, Page 7) and from published data compiled by Levenspiel, the extension of linearity through the transition region into the laminar region was unexpected. These characteristics are depicted in Figure 1, Page 15, where curves representing Taylor's turbulent-region prediction, data collected in this study, and data obtained from the literature are plotted.

Even though fair agreement is indicated between the collected data and published data for Reynolds numbers greater than 20,000, significant deviation exists for smaller Reynolds numbers. For Reynolds numbers between 3,000 and 20,000, the published dispersion intensity data decrease rapidly with increasing 
Reynolds number and range respectively between 10.0 and 0.3 , while over the same range the collected data range respectively between 0.8 and 0.15 . The anomalous behavior of the fluid dispersion existing in safe tanks, which have a comparatively small length-to-diameter ratio, is manifested by these collected data. Generally, published data would not be applicable to safe tank systems except for. high Reynolds numbers.

The scatter of collected data shown in Figure 1, Page 15, is typical of the published data, $(5,24)$ and is considerably less than exists in the Reynolds number range between 3,000 and 20,000 of the compiled data. (24)

Because the dispersion intensity is a dimensionless variable embodying the dispersion coefficient, the value was determined from an analysis of the recorder strip charts and properties of the dispersion model. For these mixing experiments, a continuous record of electrical conductivity as given by a recorder strip chart was obtained by measuring at the tank outlet or for those experiments where tank end effects were studied in the center section of a tank. Strip charts, such as shown in Figures 9 and 10 were generated. By taking measurements made at the tank inlet, the spread of the approximated tracer pulse was observed to be negligible. The assumption of pulse injection was justified. By using a set of transformation equations, the distribution of tracer concentration as a function of time (termed the exit age distribution function by Danckwerts ${ }^{(27)}$ ) was calculated. The algorithm for converting conductivity distributions to dispersion intensities is given in the Appendix. 


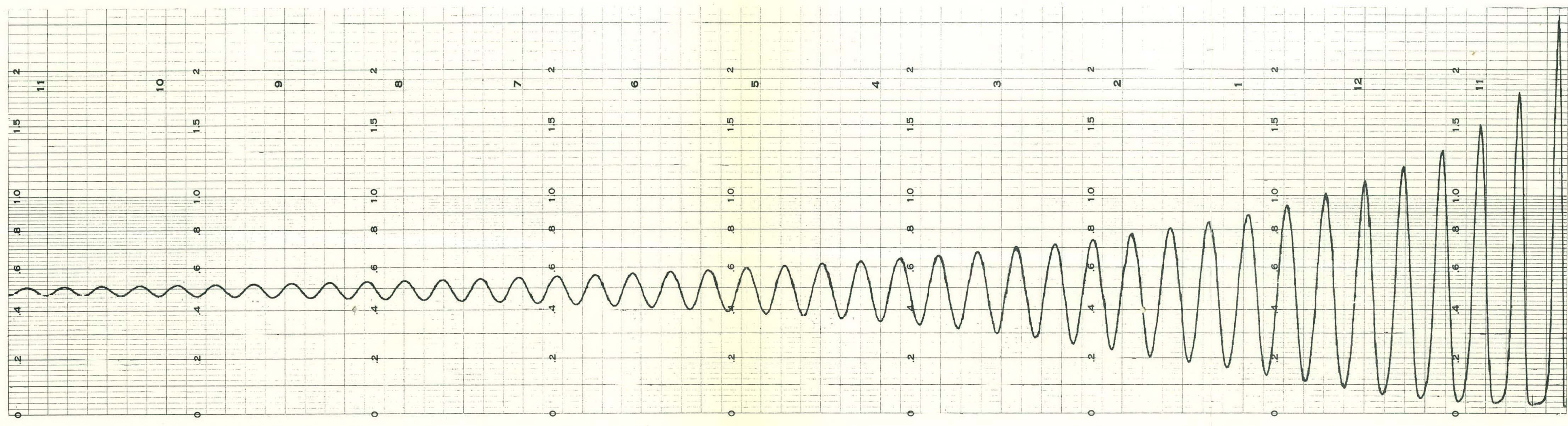

FIGURE 9

TYPICAL RECORDER STRIP CHART OBTAINED AT A RELATIVELY HIGH RECIRCULATION RATE AND AT THE TANK OUTLET (RUN 2.3, SERIES 8 AT 91.5 G.P.M.) 


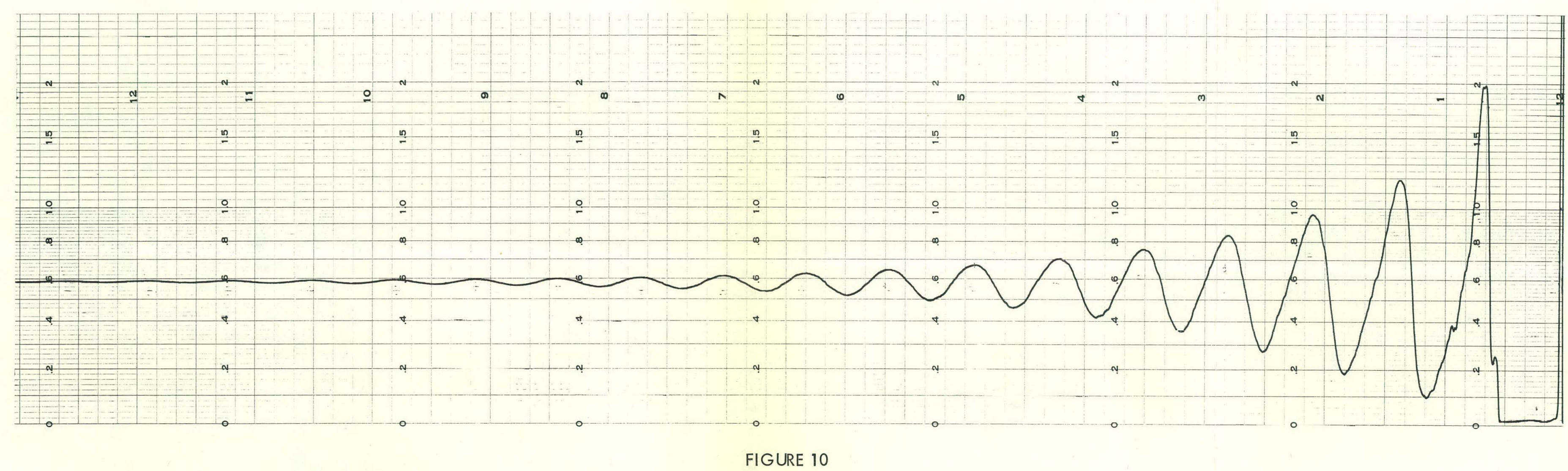

TYPICAL RECORDER STRIP CHART OBTAINED AT A RELATIVELY LOW RECIRCULATION RATE AND AT THE TANK INLET (RUN 61, SERIES 11, AT 9.7 G.P.M.) 
In an effort to determine the effect of tank end flow conditions upon the measured dispersion intensity, two series of experiments (Series 19 and 20) using experimental methods developed by Aris ${ }^{(17)}$ and Bischoff ${ }^{(16)}$ were conducted. By these methods, the requirement for the injection of a "perfect pulse" having zero variance of tracer was relieved and tracer injection of any arbitrary form was used when measurement was made at two downstream axial positions. A discussion of the method of calculating dispersion intensities for this type of experiment is presented in the Appendix. For these series, the dispersion intensity in the center $\left(14^{\prime} 6^{\prime \prime}\right.$ long) section of a 26 -foot-long by 6 -inch-diameter tank was measured. Data obtained in Series 19 were collected for this tank loop as described. Data given for Series 20 were collected under the same experimental conditions but after the insertion of a turbulence-promoting screen wire mesh (16 meshes per linear inch made of 20-mil stainless steel wire) in the tank reducers at each end. For the latter case where a relatively uniform radial velocity distribution was created at each tank end by the wire mesh and for the former case without the mesh, the center region of these tanks had about the same dispersion characteristics as those entire tanks studied. Therefore, in these experiments where about twelve diameters of pipe were available for flow developments, tank and effects were not eliminated.

The anomalous behavior of the collected dispersion-intensity data may be attributed to flow disturbances at the tank ends since dispersion is very sensitive to velocity distribution, as observed by Tickaceh, et al. (28) Based on reviews given by McCabe and Smith ${ }^{(29)}$ and by Wilkinson ${ }^{(30)}$ of the length of 
straight pipe required for the development of steady-state velocity distribution in a cylindrical pipe, it appears that for most of the tank systems and recirculation rates studied, a steady-state velocity distribution is not achieved within the tank. At best, a steady-state distribution could exist only in the center section of a tank since up to 50 pipe diameters are needed for velocity distribution development. For each series of experiments conducted, a linear correlation between the logarithm of the tracer dimensioned variance and the logarithm of the recirculation rate was observed to exist, namely:

$$
\log \left(\sigma_{t}^{2}\right)=A-B \log (Q),
$$

where:

$A$ and $B$ are correlation constants. As a consequence, these data were fit to Equation 36 by an IBM 7090 digital computer and Benson-Lehner electroplotter combination at the Oak Ridge Gaseous Diffusion Plant computer facility. Values of the constants for the fits, their standard error, and the variance of estimate for the fits are listed in Table IV. A typicical plut of the data to this eorrelation is shown in Figure 11. Although this correlation was not used in treating data for obtaining a dispersion intensityReynolds number correlation, it can be shown by a transformation of the variables that when a linear representation exists for one it ulso exists for the other correlation. The appropriate transformation relations are given in the Appendix. 
TABLE IV

CORRELATION COEFFICIENTS AND ERROR ESTIMATES

FOR THE EXPERIMENTAL DIMENSIONED VARIANCE RECIRCULATION RATE CORRELATIONS

\begin{tabular}{|c|c|c|c|c|c|}
\hline \multirow[b]{2}{*}{$\begin{array}{l}\text { Series } \\
\text { Number }\end{array}$} & \multicolumn{2}{|c|}{ Constant $A^{a}$} & \multicolumn{2}{|c|}{ Constant $B^{a}$} & \multirow{2}{*}{$\begin{array}{l}\text { Variance of } \\
\text { Estimate } \\
\text { of Fit }\end{array}$} \\
\hline & Value & $\begin{array}{c}\text { Standard } \\
\text { Error }\end{array}$ & Value & $\begin{array}{c}\text { Standard } \\
\text { Error }\end{array}$ & \\
\hline 6 & 1.356 & 0.086 & 2.302 & 0.059 & 0.012 \\
\hline 8 & 1.583 & 0.088 & 2.207 & 0.077 & 0.037 \\
\hline 16 & 1.415 & 0.075 & 2.246 & 0.046 & 0.003 \\
\hline $17 \mathrm{~h}$ & 1.571 & 0.062 & 2.338 & 0.038 & 0.002 \\
\hline $18_{h}^{b}$ & 0.793 & 0.061 & 2.124 & 0.037 & 0.002 \\
\hline $18^{\mathrm{D}}$ & 1.457 & 0.085 & 2.274 & 0.051 & 0.004 \\
\hline $19^{\circ}$ & 0.876 & 0.133 & $2: 204$ & 0.089 & 0.015 \\
\hline $19^{b}$ & 1.222 & 0.155 & 2.133 & 0.104 & 0.021 \\
\hline
\end{tabular}

${ }^{a}$ The correlation coefficients (Constants $A$ and B) fit data listed in Table VI to Equation 36.

The first and second entries for Series 18 and 19 are for the upstream and downstream variance measurements respectively. 


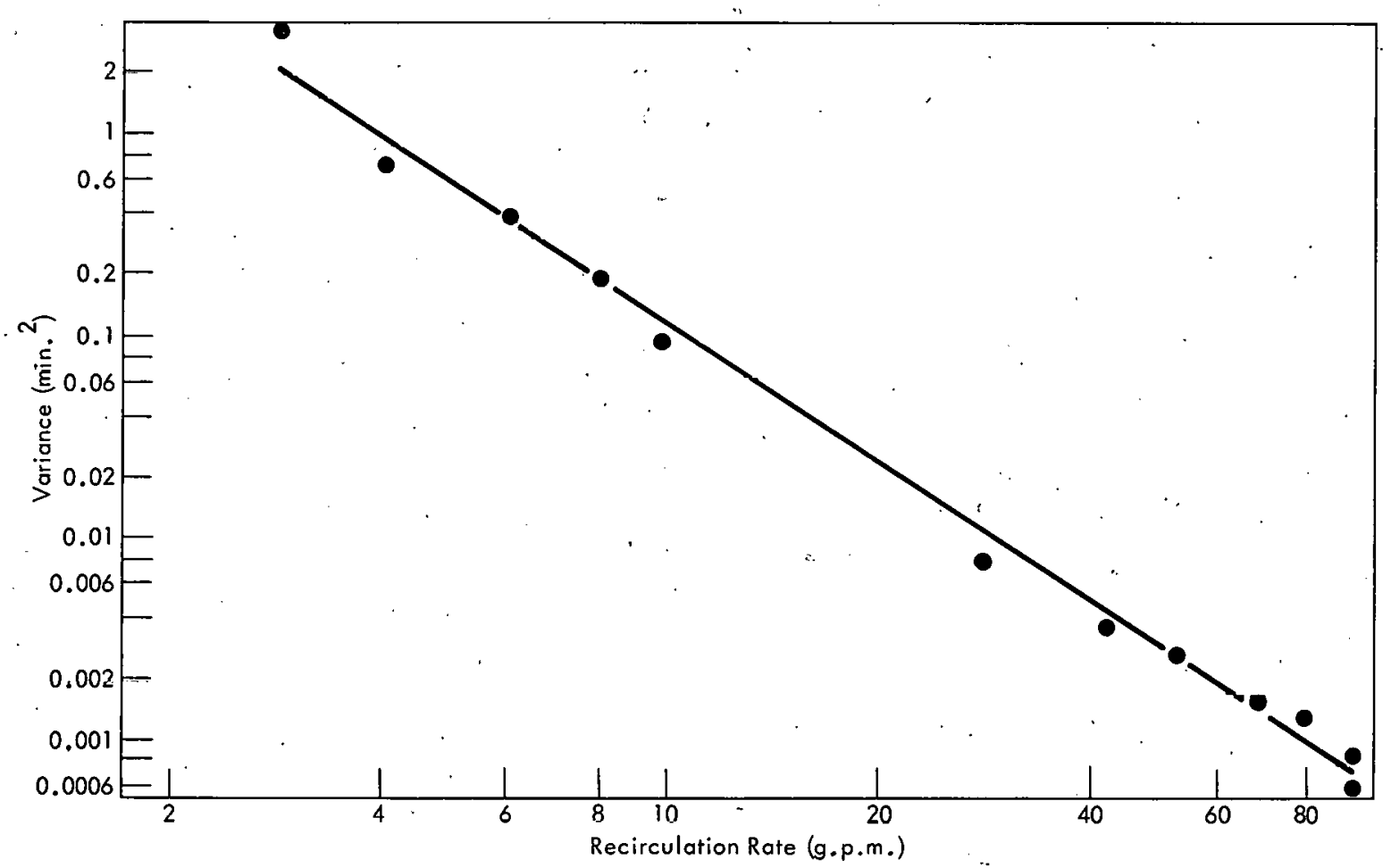

FIGURE 11

TYPICAL CORRELATION BETWEEN DIMENSIONED VARIANCE AND .THE RECIRCULATION RATE AS SHOWN FOR SERIES 6 (TABLE VI) 
Associated with each dispersion intensity must be a Reynolds number based on the mean velocity. Expressed in consistent units, the following Reynolds number equation was used:

$$
\operatorname{Re}=3,161 \frac{Q}{d},
$$

where:

$$
\begin{aligned}
& d=\text { tank diameter in inches, and } \\
& Q=\text { recirculation rate in gallons per minute. }
\end{aligned}
$$

An analysis of the variance test was made on dispersion intensity data collected in Series $6,8,16,17,18$, and 19 using the treatment suggested by Lehmann ${ }^{(31)}$ and by Mickley, et al. ${ }^{(32)}$ It was found that a single linear correlation of the form:

$$
\log \left(D_{i}\right)=a-\beta \log (R e),
$$

was statistically justified at a probability level of $95 \%$ for representation of the dispersion intensity data as a function of the Reynolds number for these tank loop systems. Correlation constants and their standard errors representative of these treated data are:

$$
\begin{aligned}
& a=0.5540, s_{a}=0.0913 ; \\
& \beta=0.2805, s_{\beta}=0.0219 .
\end{aligned}
$$

Substantiation for the single-data correlation is given in the analysis of variance tabulation of Table $V$. . 
TABLE $\vee$

ANALYSIS OF VARIANCE TABLE FOR HYPOTHESIS THAT ALL DATA

CAN BE REPRESENTED BY A SINGLE DISPERSION INTENSITY REYNOLDS NUMBER CORRELATION

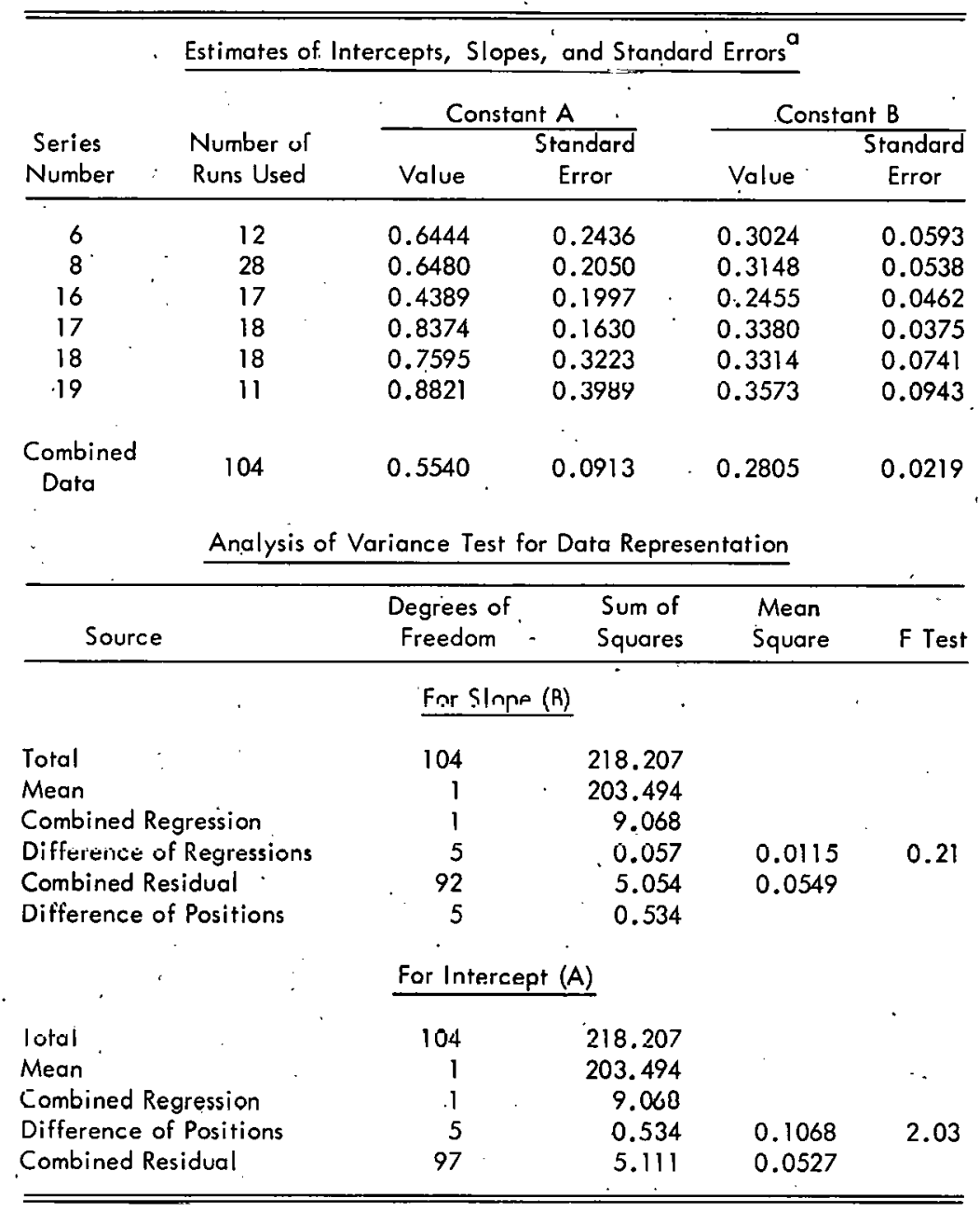

${ }^{a}$ At a 95.0 percent confidence level both hypothesis of equal slope and of equal intercept are accepted. 


\section{Mixing-Time Data}

Mixing-time determinations were made for seven horizontal tank loop systems at recirculation rates which, based on the tank diameter, extend from the laminar region into the turbulent region. These data were fit by an equation of the form:

$$
\log T=A-B \log Q,
$$

where:

$$
\begin{aligned}
& T=\text { mixing time (minutes) } \\
& Q=\text { recirculation rate (gallons per minute), and }
\end{aligned}
$$

$A$ and $B=$ constants of the least-squares data fit.

This relationship is intuitively acceptable because in the limiting conditions of zero and infinite recirculation rates, the mixing time should approach limiting values of infinity and zero. This fact is exhibited by the antilogarithmic form of the equation:

$$
T=10^{A} Q^{-B} \quad \text { where: }\left\{\begin{array}{l}
T \rightarrow \infty \text { for } Q \rightarrow 0, \text { and } \\
T \rightarrow 0 \text { for } Q \rightarrow \infty,
\end{array}\right.
$$

when the limiting values of the recirculation rate are introduced. For these reasons, all mixing-time data were fit to Equation 39 by least-squares methods.

For a determination of the mixing time, the periodic character of the conductivity curve on a strip chart; which approximates an exponentially decaying sine function, was used. By following the periodic maxima along a chart, as shown by Figures 9 and 10, Pages 44 and 45, the magnitude of the difference between 
adjacent conductivity maxima and minima is seen to approach a limiting value for the system which is tracer homogeneous with the system bulk contents. It was found that a mixed condition, defined by Equation 28, Page 21, where $\gamma \geq 0.995$, could be consistently detected because of the smoothness and periodicity of the strip-chart conductivity curve. Based on this ability, a mixed condition was defined to exist one period past the last discernable maximum. This measure of mixing time was somewhat arbitrary due to the difficulty in selecting the correct final maximum. However, a mixing time based on conductivity maxima is the time required after an integral number of tracer circulations for the concentration maxima to decay to a condition where relative homogeneity is defined to exist. It is then only an approximate measurement and may be in error by a few periods. Due to the accepted mixing time criteria, a mixed condition exceeding $\gamma \geq 0.995$. must exist. This condition was assumed to be approximately $\gamma \geq 0.998$.

After locating the appropriate maxima, a measurement was made of the length of chart from the start of a run to the last maximum plus one period. After computing the chart rate, $r$, from the formula:

$$
r=\frac{D_{f}-D_{0}}{t_{f}}
$$

where:

$$
\begin{aligned}
& D_{f}=\text { displacement of the strip chart from the reference point when the } \\
& \text { experiment was terminated (inches), }
\end{aligned}
$$


$D_{0}=$ displacement of the strip chart from the reference point when the experiment was initiated (inches), and

$$
t_{f}=\text { measured experiment time. (minutes), }
$$

the mixing time was calculated by the formula:

$$
t_{m}=\frac{D_{m}-D_{o}}{r},
$$

where:

$D_{m}=$ displacement of the strip chart from the reference point to one period past the last discernable maximum measured in inches.

Mixing-time data obtained in this way have been listed in Table VI for each experimental series. Data for each experimental series were treated by a least-squares fit to Equation 39 and plotted using an IBM 7090, digital computer and Benson-Lehner electroplotter combination at the Oak Ridge Gaseous Diffusion Plant computer facility. Plots of these data are presented in Figures 12 through 18. Values of constants for the fits, their standard error, and the variance of estimate for the fits are listed in Table VII.

For all experimental series, the linear correlation between the logarithm of the mixing time and the logarithm of the recirculation rate was found to represent data reasonably well. However, the correlation for data collected in Series 24 and 26, from tank systems with the largest length-to-diameter ratios considered. $(L / d=80)$, did not represent data nearly as well as for the tank systems with smaller length-to-diameter ratios $(30<L / d<75)$. Data for these series, plotted 
TABLE VI

EXPERIMENTAL MIXING TIME' AND DIMENSIONED VARIANCE DATA TABULATION

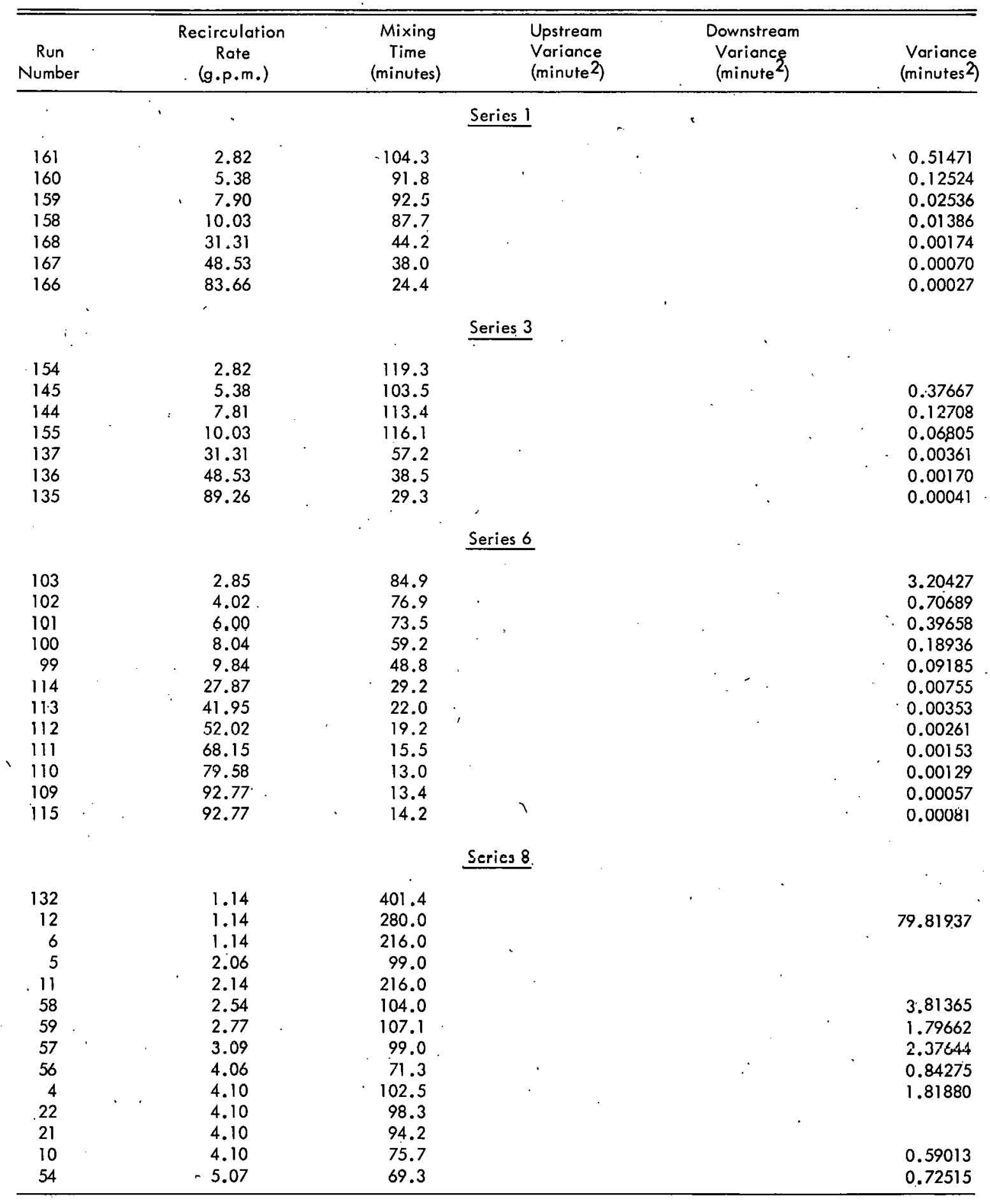


TABLE VI (Continued)

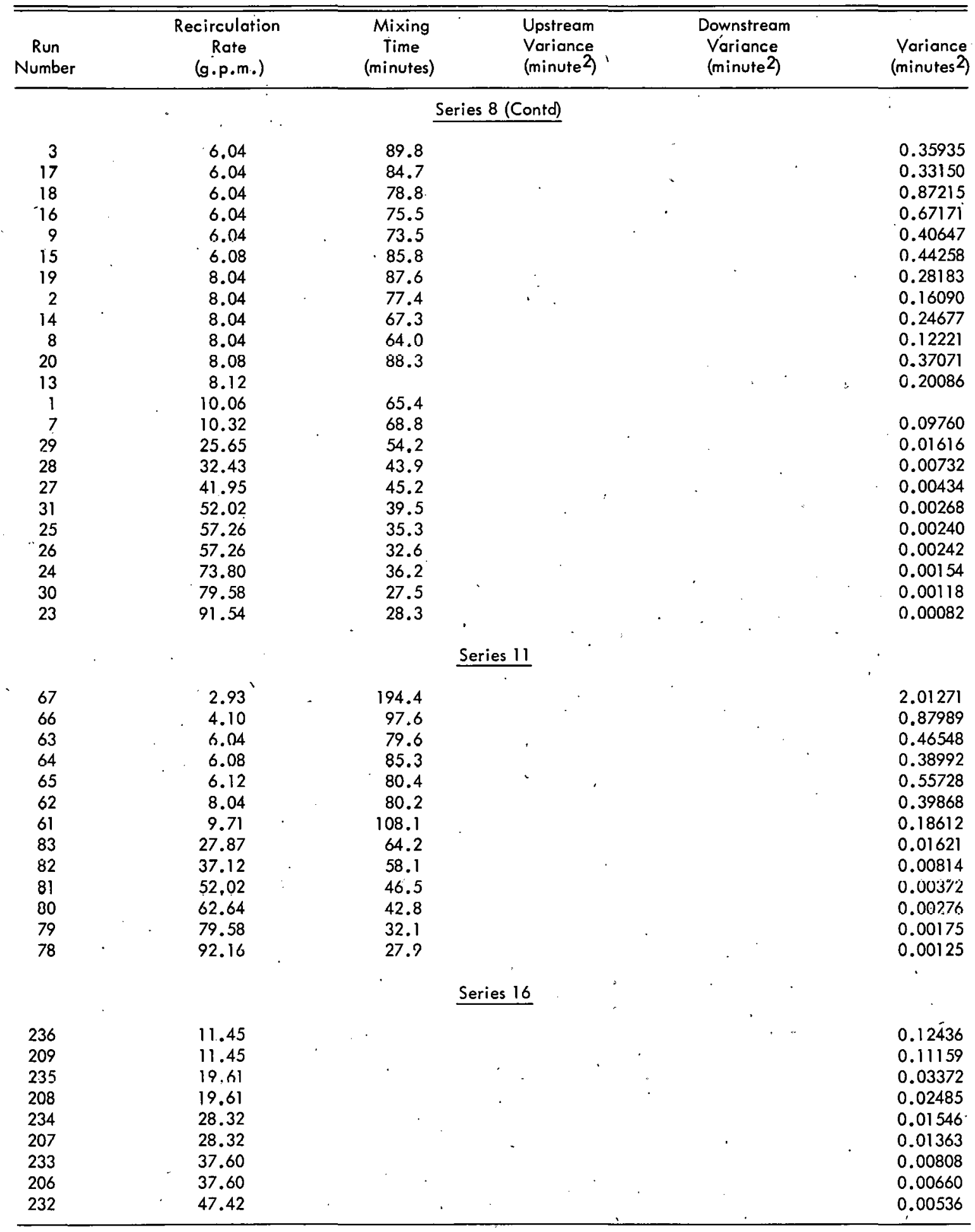


TABLE VI (Continued)

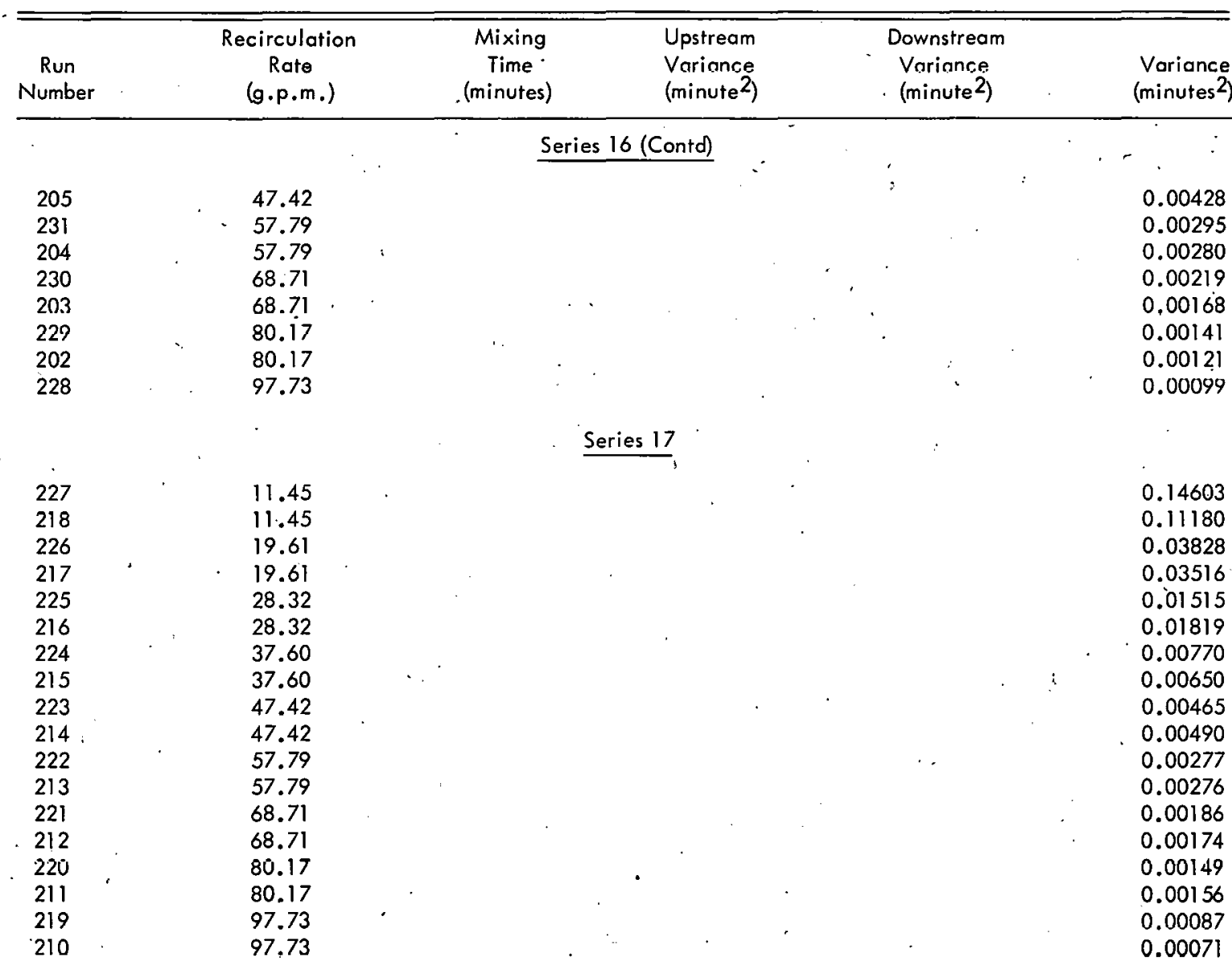

Series 18

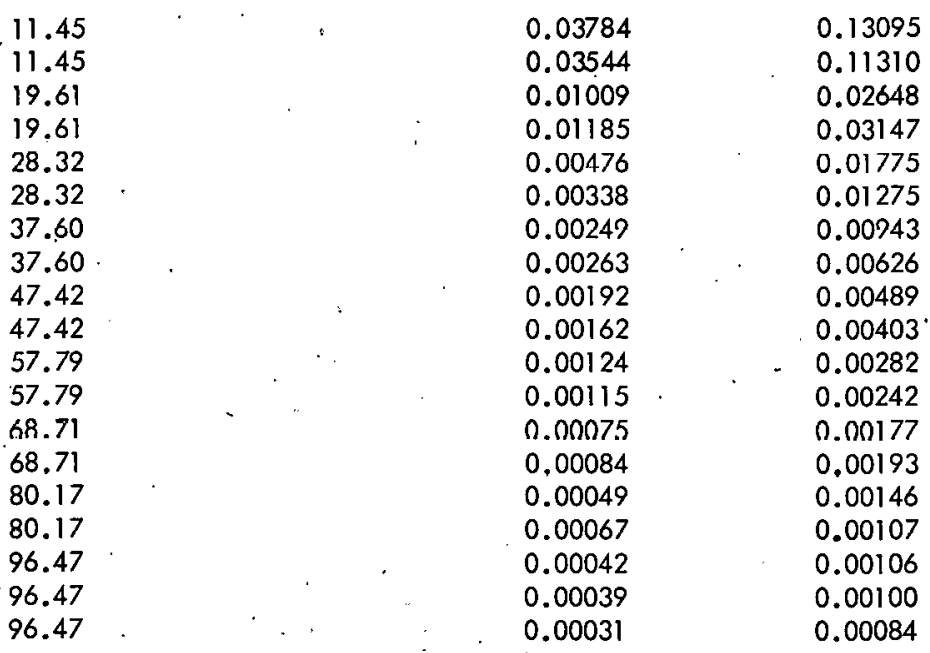


TABLE VI (Continued)

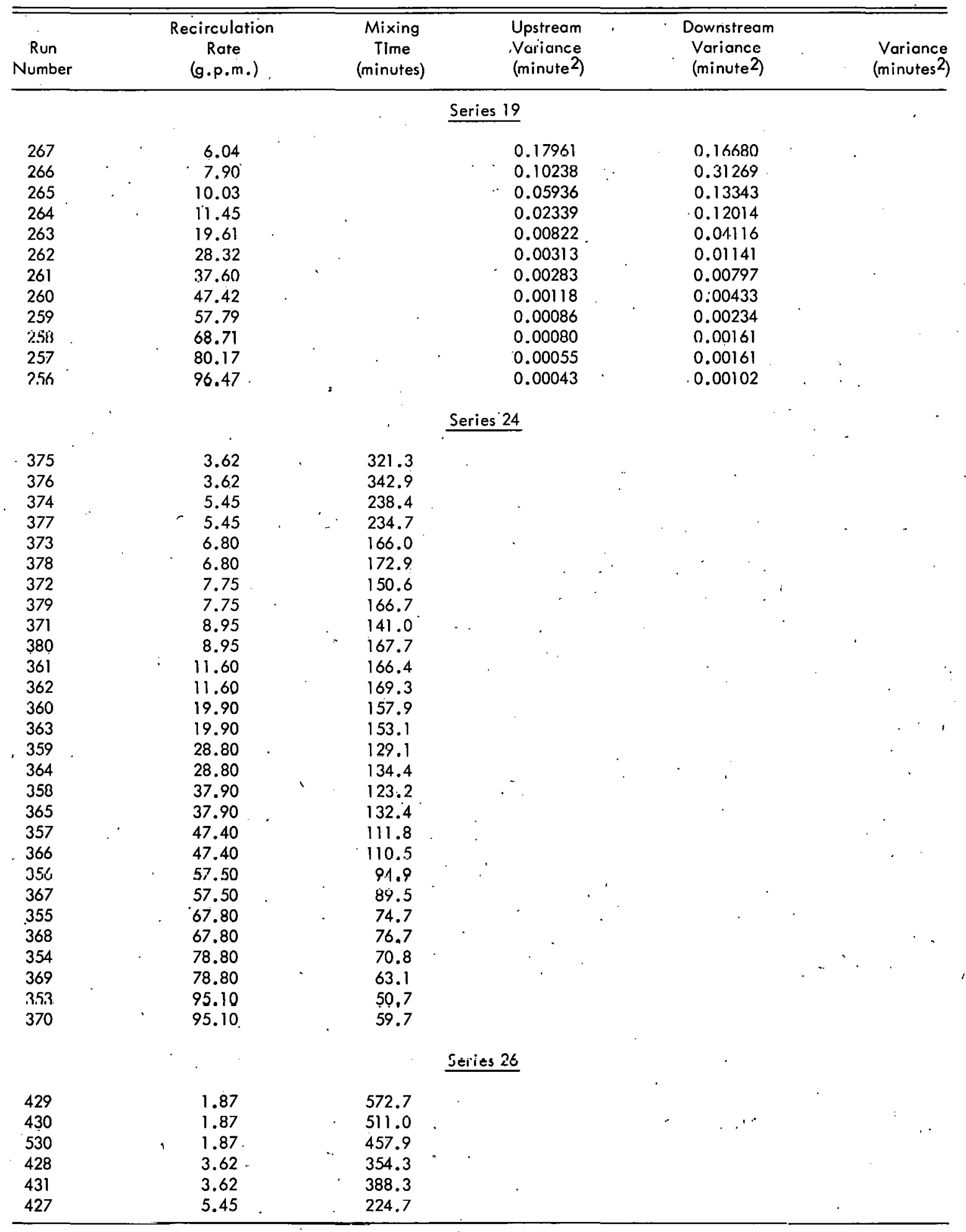


TABLE VI (Continued)

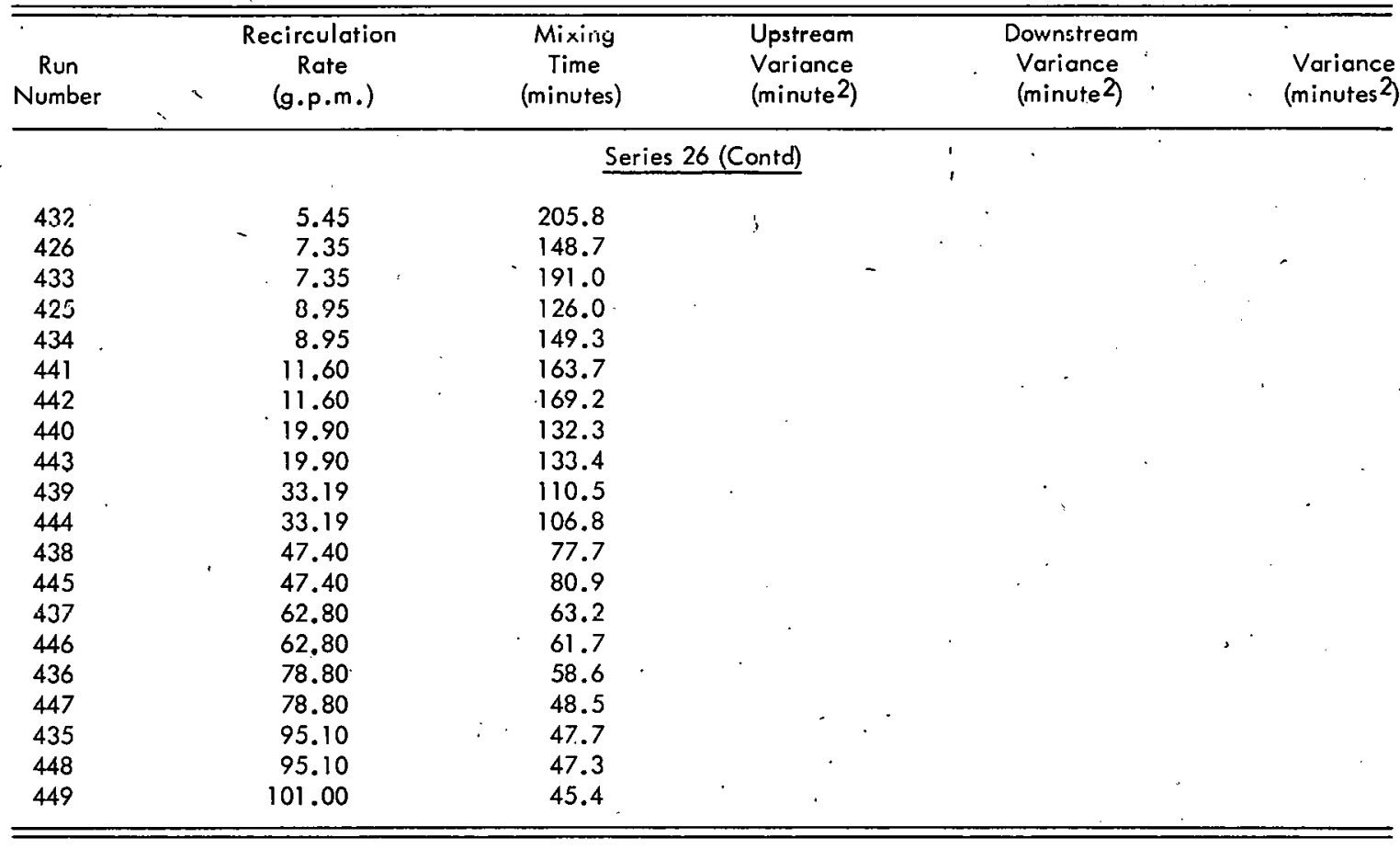




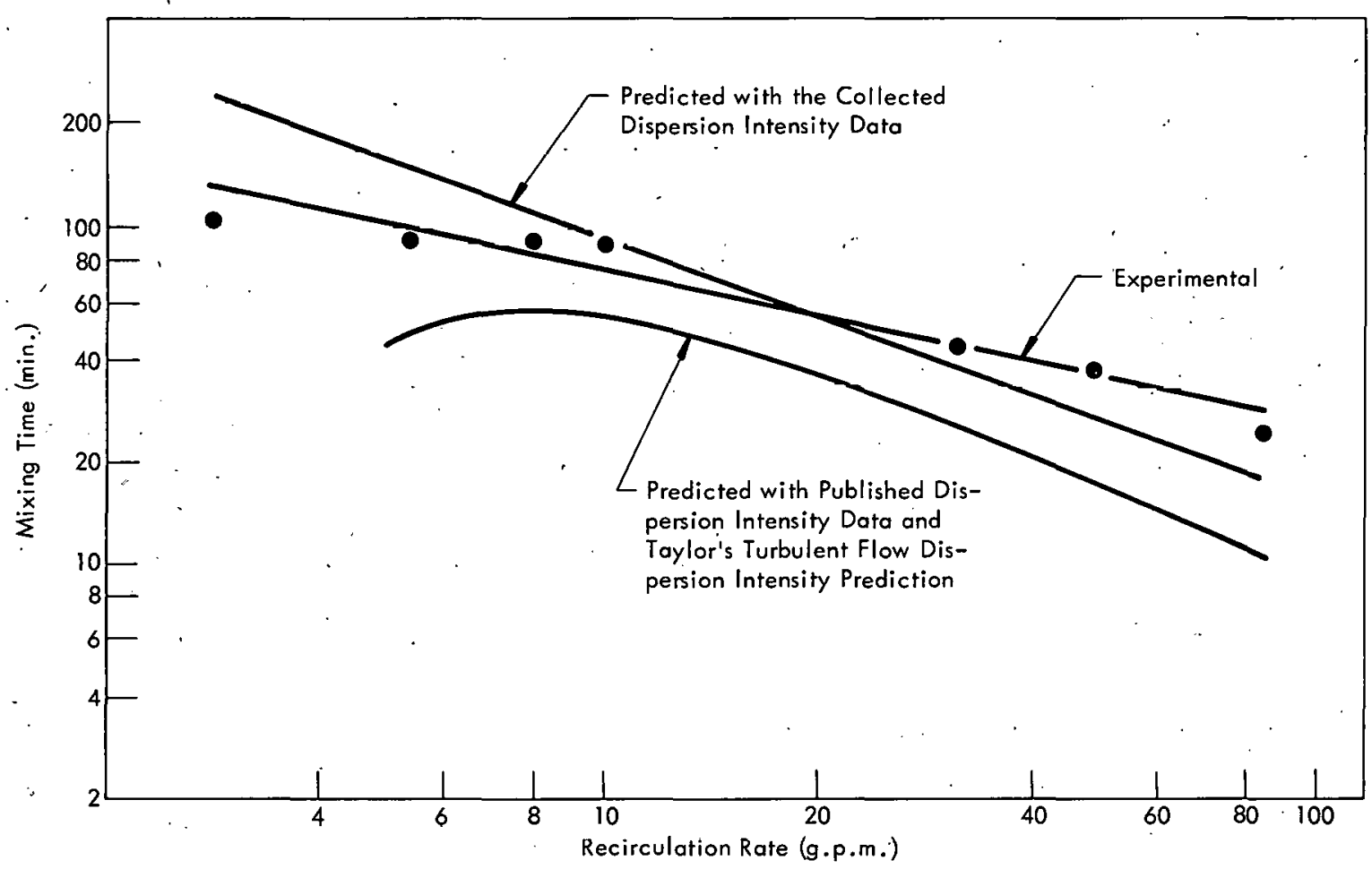

FIGURE 12

EXPERIMENTAL AND PREDICTED MIXING TIMES AS FUNCTIONS OF THE RECIRCULATION RATE FOR SERIES 1 (TABLE VI) 


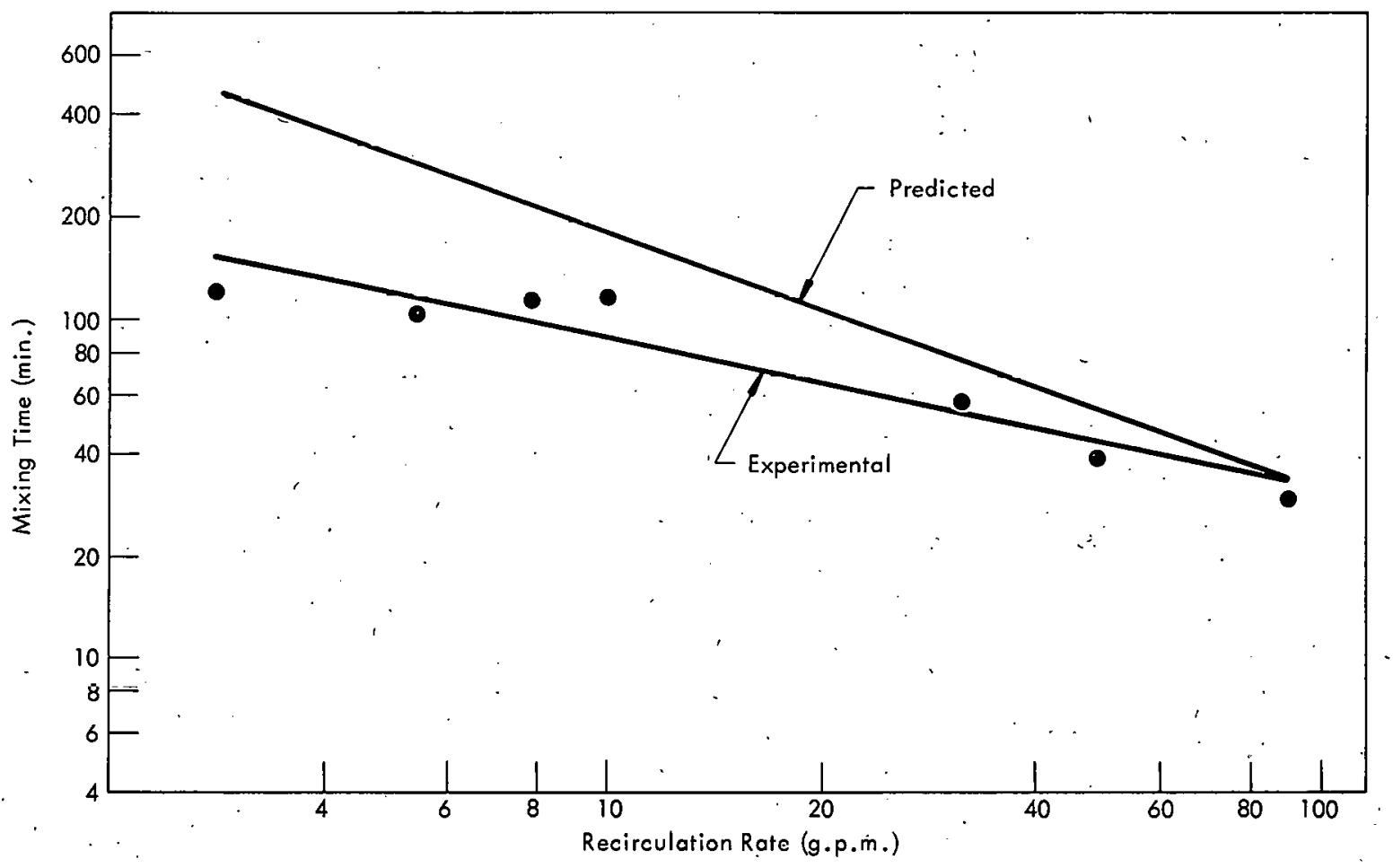

FIGURE 13

EXPERIMENTAL AND PREDICTED MIXING TIMES AS FUNCTIONS OF THE RECIRCULATION RATE FOR SERIES 3 (TABLE VI) 


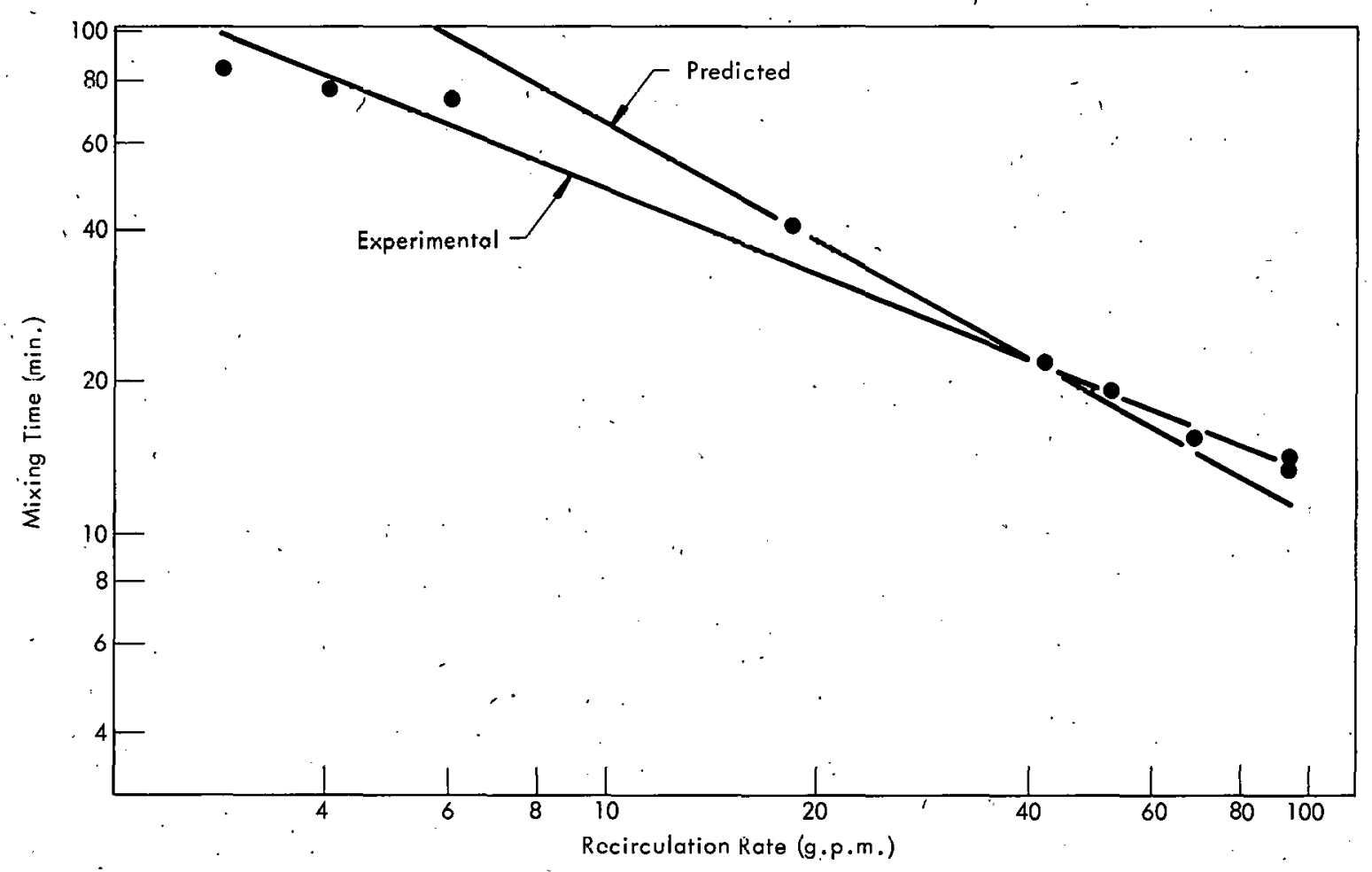

FIGURE 14

EXPERIMENTAL AND PREDICTED MIXING TIMES AS FUNCTIONS OF: THE RECIRCULATION RATE FOR. SERIES 6 (TABLE VI) 


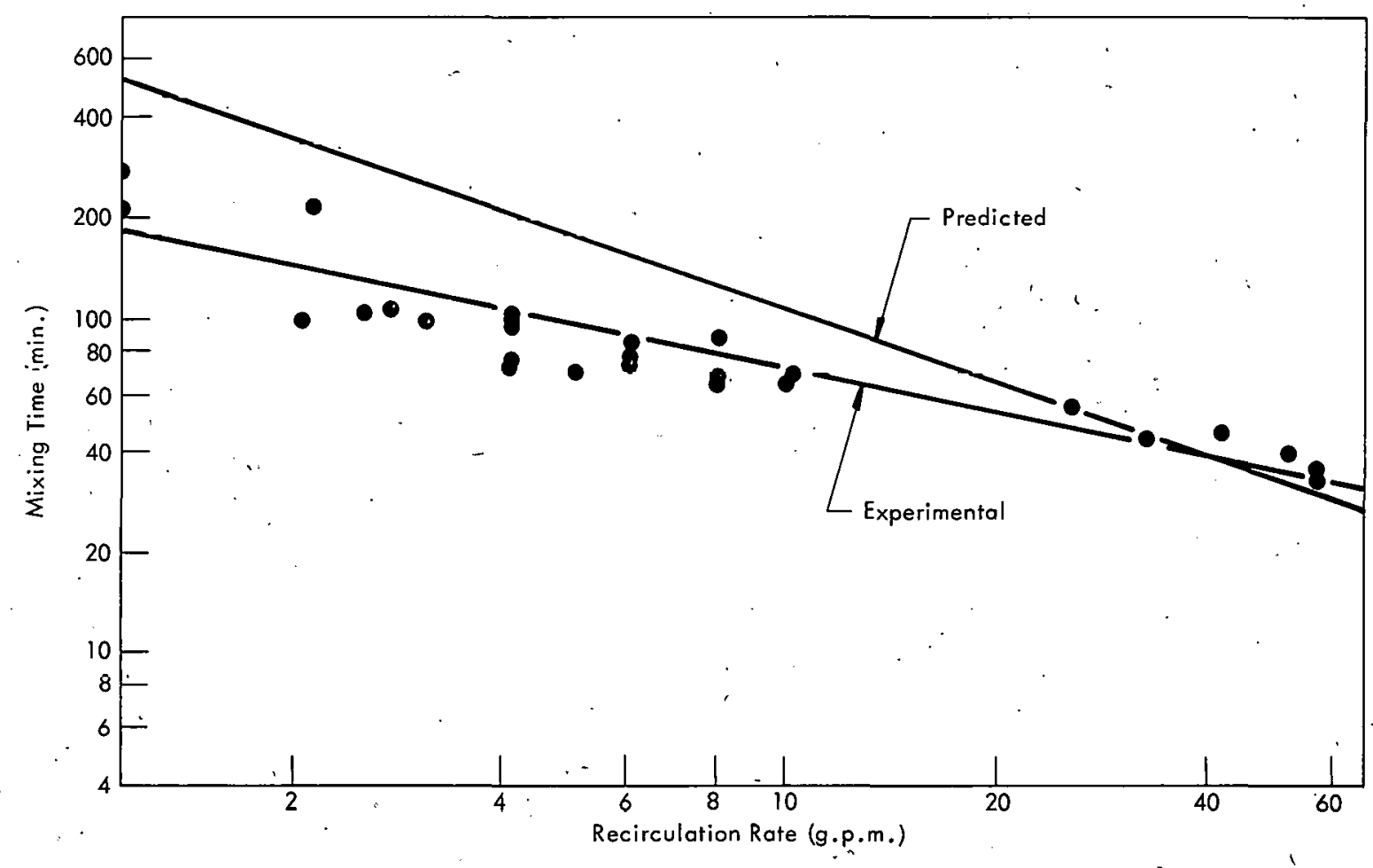

FIGURE 15

EXPERIMENTAL AND PREDICTED MIXING TIMES AS FUNCTIONS OF THE RECIRCULATION RATE FOR SERIES 8 (TABLE VI) 


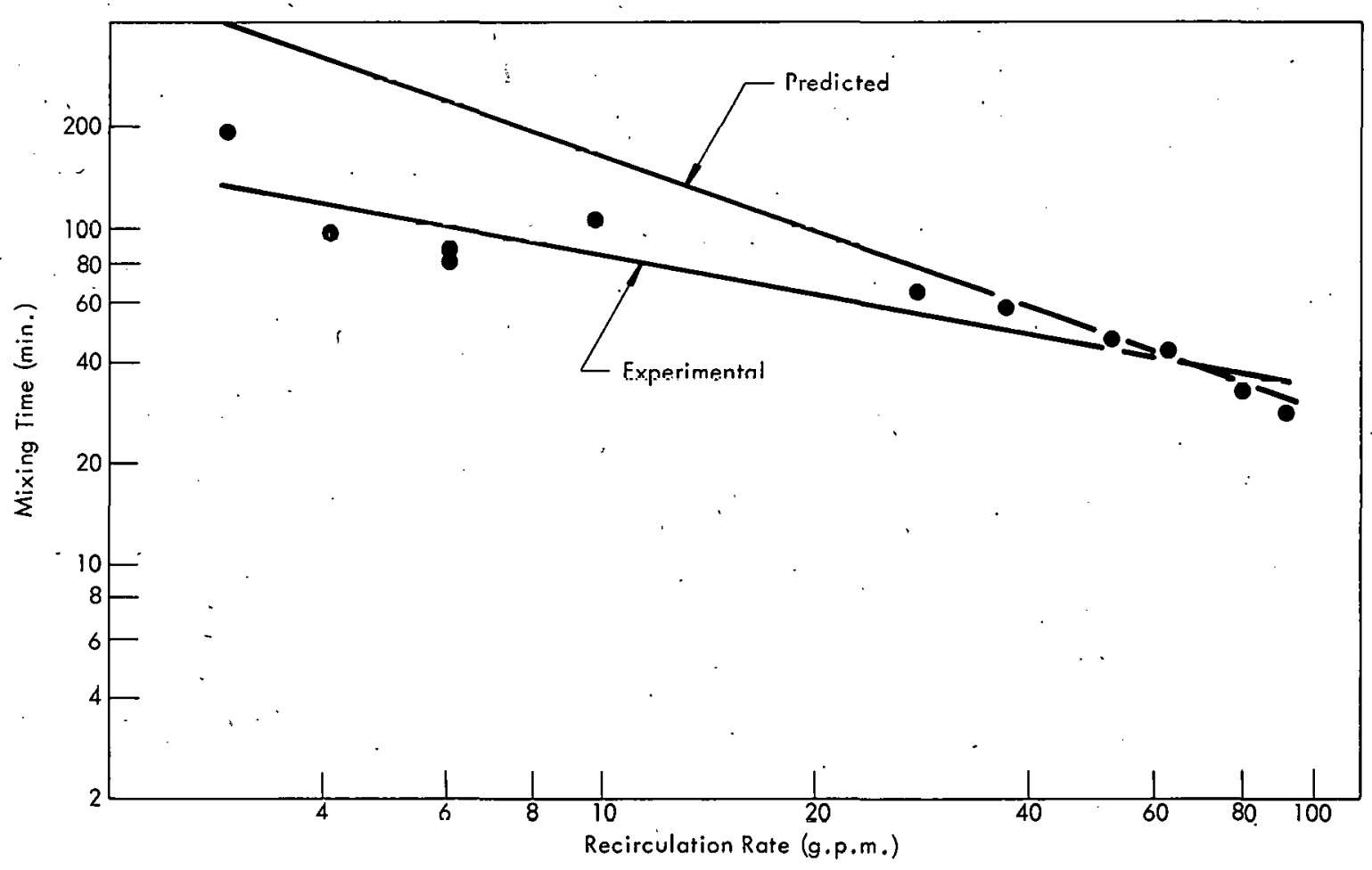

FIGURE 16

EXPERIMENTAL AND PREDICTED MIXING TIMES AS FUNCTIONS OF THE RECIRCULATION RATE FOR SERIES 11 (TABLE VI) 


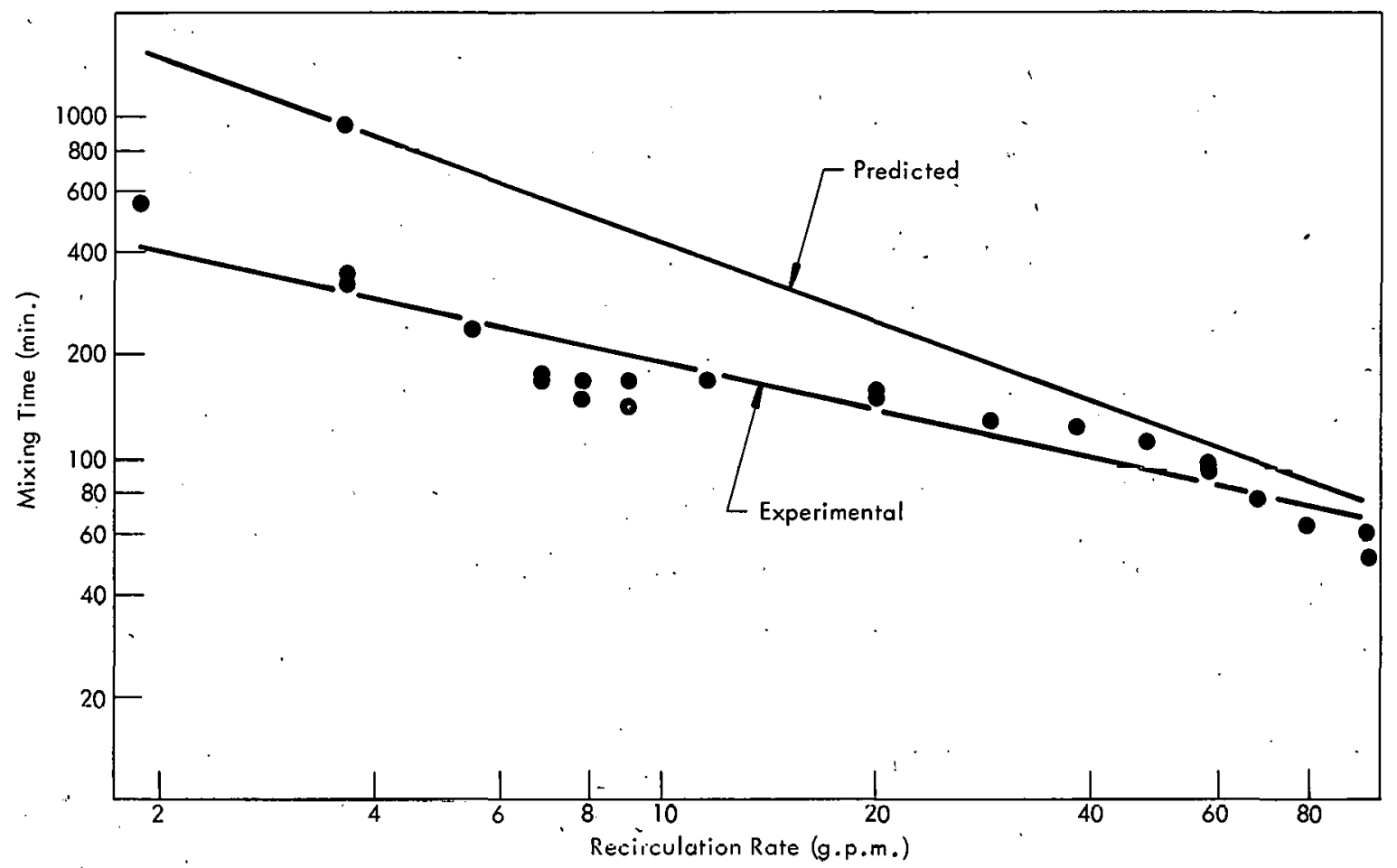

FIGURE 17

EXPERIMENTAL AND PREDICTED MIXING TIMES AS FUNCTIONNS OF THE RECIRCULATION RATE FOR SERIES 24 (TABLE VI) 


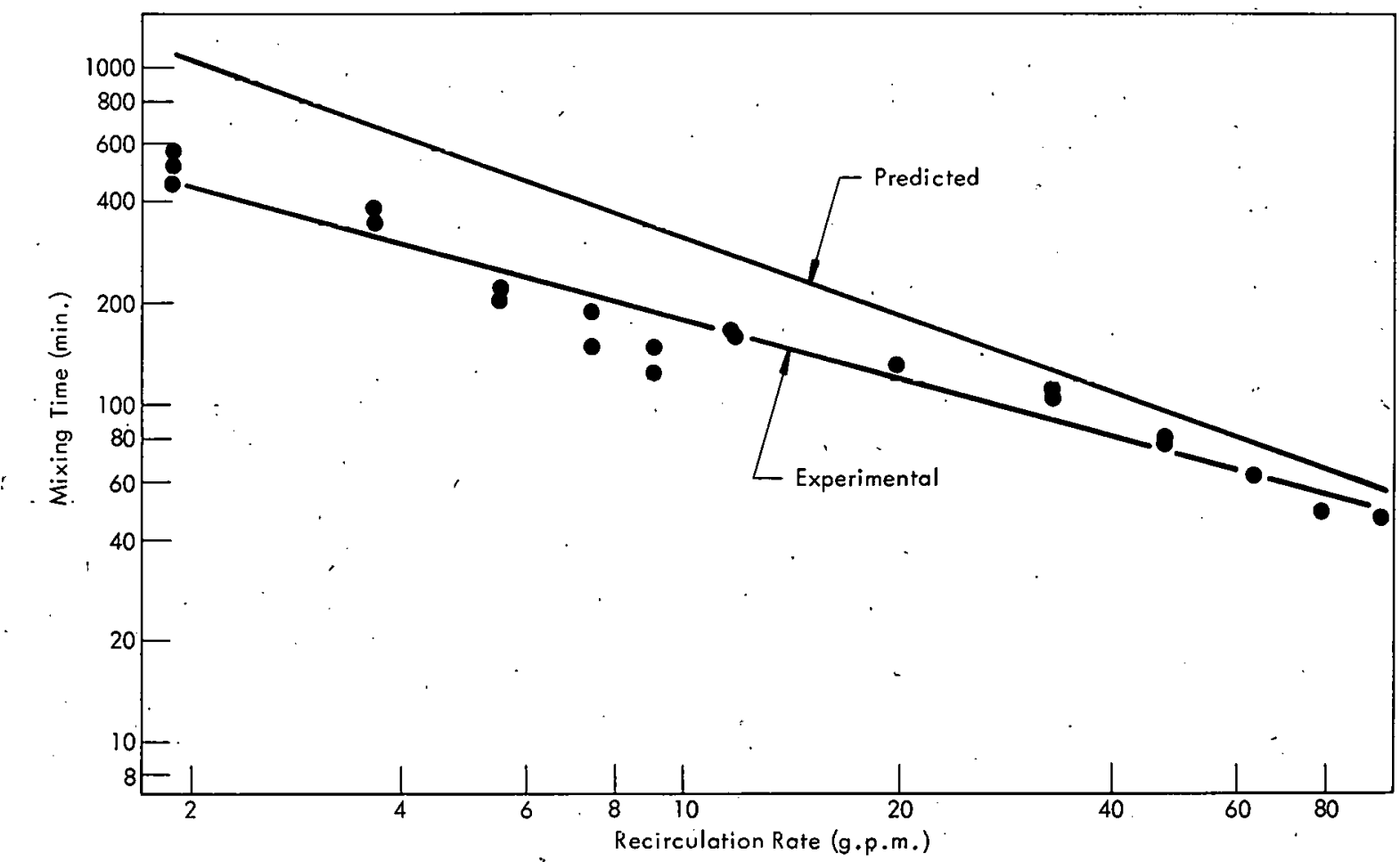

FIGURE 18

EXPERIMENTAL AND PREDICTED MIXING TIMES AS FUNCTIONS OF THE RECIRCULATION RATE FOR SERIES 26 (TABLE VI) 
TABLE VII

CORRELATION CONSTANTS AND ERROR ESTIMATES

FOR THE EXPERIMENTAL MIXING TIMERECIRCULATION RATE CORRELATIONS

\begin{tabular}{|c|c|c|c|c|c|}
\hline \multirow[b]{2}{*}{$\begin{array}{l}\text { Series } \\
\text { Number }\end{array}$} & \multicolumn{2}{|c|}{ Constant A } & \multicolumn{2}{|c|}{ Constant B } & \multirow{2}{*}{$\begin{array}{l}\text { Variance of } \\
\text { Estimate } \\
\text { of Fit }\end{array}$} \\
\hline & Value & $\begin{array}{c}\text { Standard } \\
\text { Error }\end{array}$ & Value & $\begin{array}{l}\text { Standard } \\
\text { Error }\end{array}$ & \\
\hline 1 & 2.302 & 0.065 & 0.441 & 0.051 & 0.005 \\
\hline 3 & 2.378 & 0.085 & 0.442 & 0.067 & 0.008 \\
\hline 6 & 2.251 & 0.030 & 0.568 & 0.020 & 0.001 \\
\hline 8 & 2.284 & 0.034 & 0.437 & 0.032 & 0.011 \\
\hline 11 & 2.305 & 0.066 & 0.394 & 0.050 & 0.009 \\
\hline 24 & 2.764 & 0.042 & 0.476 & 0.030 & 0.007 \\
\hline 26 & 2.813 & 0.033 & 0.567 & 0.025 & 0.005 \\
\hline
\end{tabular}


in Figures 17 and 18, exhibit three distinct mixing regions. When the recirculation rates which divide these regions are expressed in terms of tank Reynolds numbers, the division between the first two regions occurs at about $\operatorname{Re}=4,000$ and between the second and third regions at about $\operatorname{Re}=16,000$. For both the low and the high ranges of recirculation rate, a linear data correlation was indicated by carefully noting the data location in these ranges. Within the intermediate range of recirculation rate, a transition mixing region was noted where mixing time is nearly constant and independent of the recirculation rate. Even for tank systems with smaller length-to-diameter ratios, an inset of this anomalous transition mixing region found in the longer systems is detectable, as can be noted in Figures 12 and 13, Pages 60 and 61.

The effect of the tracer addition upon the mixing time was considered by modifying the method of tracer addition and repeating the experiments on the same tank loop system. This was accomplished in Series 24 and 26 where comparison was made to Series 24 which used the approximate pulse injection method. For Series 26, tracer was added just inside the tank at the low end reducer and allowed to stratify by virtue of its greater density. This latter method simulates initial conditions prevalent in slightly inclined horizontal tank loops that are filled intermittently. By comparing the plots of the data for these series, given in Figures 17 and 18 , the effect is indetectable in the lower range of the recirculation rate. However, at the higher rates, the pulse-injection mixing-time data are as much as $25 \%$ higher. For the higher rate this observation is not surprising since the initial 
amount of tracer dispersion is far less. Ideally no dispersion exists for pulse injection. Some period of time would be needed to disperse a pulse-injected tracer to' as great an extent as would initially exist from tracer addition directly into the tank and allowing the tracer to disperse by gravity. At the lower recirculation rates, where mixing times were about the same, the effect of gravity upon the tracer pulse during the first several circulations is highly significant. As noted by observing the greenish-colored tracer at the lower rates, the tracer pulse would gravitate during flow and tend to lag. By virtue of this lagging, tracer was gravitationally dispersed in somewhat the same manner and to about the same degree as existed in the modified method of tracer addition.

Comparison of Theoretical and Experimental Mixing Times

Based on the linear correlation of the logarithms of mixing time and rem circulation rate for each experimental series using Equation 39, Page 52, and assuming that these data were collected for a mixed condition with $\gamma \geq 0.998$, a comparison was made with the mixing time predicted by the developed theory for the range of recirculation rates experimentally studied. The dispersion intensityReynolds number correlation obtained in this study for all collected data was used for calculating the overall loop system mixing number following procedures previously outlined. The correlation was applied both to the tanks and also their associated loop piping. The system pump was treated as an ideally mixed tank. 
Two sets of mixing-time calculations were made for comparison. One accounted for the dispersion that was expected to exist outside the tanks as previously mentioned; the other disregarded this dispersion. The mixing time comparisons given in Figures 12 through 18, Pages 60 through 66, include the contribution of loop piping in the mixing number .

Neglected dispersion outside the tank amounted to only about $3 \%$, which is small compared with the uncertainty inherent in the predicted mixing time. Until a more accurate mixing number prediction for a tank can be made which will account for end effects, an analysis. which includes the dispersion outside of a tank seldom may be needed.

To test the mixing theory at a mixed condition other than $\gamma=0.998$, which has been used throughout this study, a comparison was made for $\gamma=0.90$. Strip charts obtained in Series 1 were used to obtain experimental mixing-time data. These experimental data were fit to Equation 39, Page 52, and plotted in Figure 19 along with the predicted mixing-time curve. The predicted mixingtime curves are seen to fit the collected data at both mixed conditions equally well. It is significant to note that the ratio of predicted mixing times at mixed conditions of 0.998 and 0.90 agree with the experimental data. This relationship is shown by the Series 1 data plotted in Figure 12, Page 60, and Figure 1.9 at recirculation rates of 10 and $50 \mathrm{~g} \cdot \mathrm{p} . \mathrm{m}$. At these recirculation rates the ratio:

$$
\frac{\left(t_{m}\right)_{\gamma}=0.998}{\left(t_{m}\right)_{\gamma}=0.90}
$$




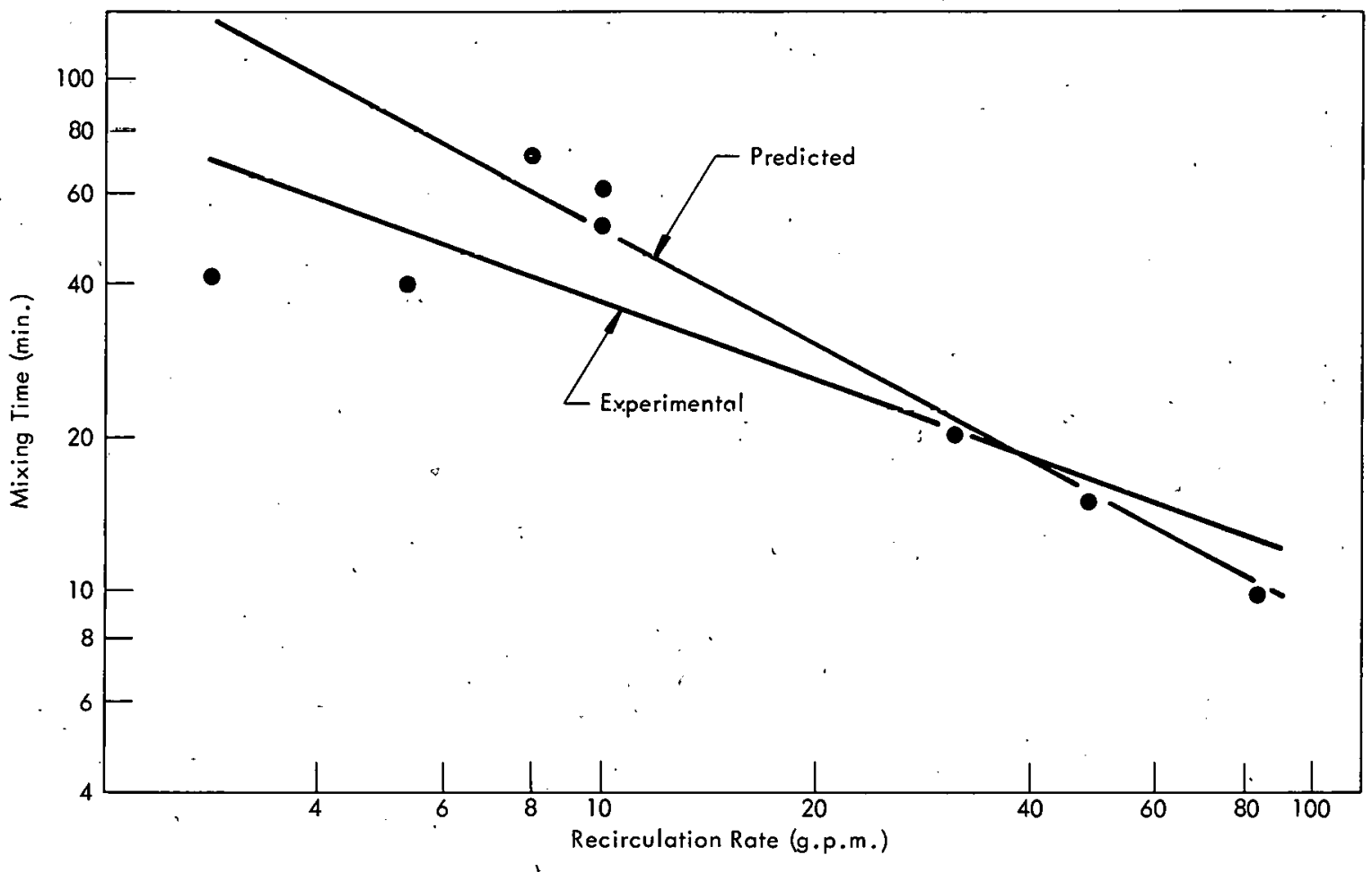

FIGURE 19

EXPERIMENTAL AND PREDICTED MIXING TIMES AT A MIXED CONDITION OF 0.90 AS FUNCTIONS OF THE RECIRCULATION RATE FOR. SERIES 1 
for both experimental and predicted mixing times closely equals 2.3 .

Based upon the published dispersion-intensity data for Reynolds numbers between 2,100 and $20,000^{(24)}$ and upon Taylor's turbulent flow prediction for Reynolds nunbers greater than $20,000,{ }^{(8)}$ a comparison was made between predicted and experimental mixing times. A typical comparison is given in Figure 12, Page 60. In this plot, the curve representing this predicted mixing time is everywhere lower than the experimental data by about $50 \%$; however, its shape better fits the data than the predicted mixing-time curve based on a linear correlation of the dispersion intensity data collected in this study. The better-shape comparison results from the nonlinear behavior of the published data at low Reynolds numbers where dispersion intensity rapidly decreases with increasing Reynolds number. The shape comparison suggests that a different correlation for dispersion intensity data, than Equation 38, Page 50, used in this work, would better account for similar nonlinear behavior that may exist at low Reynolds numbers and better-fit mixing-time data. 


\section{NOMENCLATURE}

SYMBOL

\section{DEFINITION}
A
Constant term
Constant term
C
Dimensionless conceptration, $\mathrm{cV} / \mathrm{V}_{0}$
$C(X, \theta)$
Dimensionless concentration as a function of both time and location
co
Concentration defined in Equation 12, Page 9
$\mathrm{C}_{\mathrm{p}}$
Periodic concentration maximum
$C_{\infty}$
Steady-state concentration
$C_{N}$
Concentration defined in Equation 14, Page 10
c
Dimensioned concentration
D
Dispersion coefficient
$\mathrm{D}_{v}$
Molecular diffusion çoefficient
$\mathrm{Di}$
Dispersion intensity, $D / U d$
$D_{0}$
$D_{1}$
Strip-chart reference point
$D_{f}$
$D_{m}$
Strip-chart displacement
Total strip-chart displacement for any experiment
Strip-chart displacement equivalent to the mixing time
d
Tank diametér
$E$
Constant term
$\mathrm{F}$
Constant term 
SYMBOL

DEFINITION

Fanning friction factor

i

Subscripting index

Subscripting index

K

Solution electrical conductivity

L

Length of test section

$N$

Tank number designation for tanks-in-series model

P

Mixing number, D/UL

Q

Volumetric recirculation rate

q

Volumetric flow rate between ideally mixed tanks

$\mathrm{R}$

Rotameter scale reading

$\operatorname{Re}$

Reynolds number

Strip chart drive rate

$\mathrm{S}$

Source term for any fluid component within a differential element

$S$

$s_{\beta}$

I

t

$t_{m}$

$t_{f}$

Standard error of $a$

a

Standard error of $\beta$

Dimensiunless mixing time

$\bar{f}$

U

Time

Dimensioned mixing time

Total experiment run time

Mean residence time, $V / Q$

Mean fluid velocity 
V

Vo

$\bar{v}$

$v$

$x$

Z

$a$

$\beta$

$\gamma$

$\delta(t)$

$\delta(\theta)$

$\delta(x)$

$\eta$

$\theta$

$\mu$

$\sigma^{2}$

$\sigma_{t}^{2}$

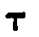

Volume of piping section or total system volume

Volume of injected tracer

Velocity vector

Velocity distribution lacross a pipe

Dimensionless axial poșition, $\mathrm{Z} / \mathrm{L}$

Dimensioned axial position

Constant term

Constant term

End-mixed condition parameter, defined by Equation 28, Page 21

Dirac delta function of time, $t$

Dirac delta function of time, $\theta$

Dirne delta function of position, $X$

Pass number index

Dimensionless time, Ut/ $\mathrm{V}$

Dimensionless mean of exit age distribution function

Dimensionless variance of exit age distribution function

Dimensioned variance of exit age distribution function

Time increment 


\section{REFERENCES}




\section{REFERENCES}

1. Harrell, J. E., Jr., The Mixing and Sampling of Enriched U-235 Fluids in Cylindrical Storage Containers, Y-DA-722, Union Carbide CorporationNuclear Division, Y-12 Plant, Oak Ridge, Tennessee (1964), unpublished.

2. Harrell, J. E., Jr., The Mixing and Sampling of Enriched.U-235 Fluids in Cylindrical Storage Containers, $Y-1502$, Union Carbide CorporationNuclear Division, Y-12 Plant, Oak Ridge, Tennessee (1966), to be issued.

3. Levenspiel, O. and Bischoff, K. B., "Patterns of Flow in Chemical Process Vessels," Advances in Chemical Engineering, pp. 95-192, Academic Press, Inc., New York (1963).

4. Jost, W., Diffusion in Solids, Liquids, Gases, Second Edition, Academic Press, Inc., New York (1960).

5. Bischoff, K. B., Fluid Dispersion - Generalization and Comparison by Mathematical Models, Ph.D. Thesis, Illinois Institute of Technology (January 1961).

6. Bischoff, K. B. and Levenspiel, O., "Fluid Dispersion - Generalization and Comparison of Mathematical Models - I Generalization of Models," Chem. Engr. Sci., 17, pp. 245-255 (1962).

7. Taylor, G. I., "Dispersion of Soluble Matter in Solvent Flowing Slowly Through a Tube," Proc. Roy, Soc. (London), A219, pp. 186-203 (1953).

8. Taylor, G. I., "The Dispersion of Matter in Turbulent Flow Through a Pipe," Proc. Roy. Soc. (London), A223, pp. 446-468 (1954).

9. Levenspiel, O. and Smith, W. K., "Notes on the Diffusion-Type Model for the Longitudinal Mixing of Fluids in Flow," Chem. Engr. Sci., 6, pp. 227233 (1957).

10. Carberry, J. J. and Bretton, R, H., "Axial Dispersion of Mass in Flow through Fixed Beds," A.I.Ch.E.J., $\stackrel{4}{=}$, pp. 367-375 (1958).

11. Ebach, E. A. and White, R. R., "Mixing of Fluids Flowing through Beds of Packed Solids," A.I.Ch.E.J., 4, pp. 161-169 (1958). 
12. Houston, R. H., A Theory for Industrial Gas-Liquid Chromatographic Columns (Thesis), University of California Radiation Laboratory Report, UCRL-3817 (April 1958).

13. Robinson, J. M., Longitudinal Dispersion in Beds of Finely Divided Solids, University of California Radiation Laboratory Report, UCRL-9193 (1960).

14. Wehner, J. F. and Wilhelm, R. H., "Boundary Conditions of Flow Reactor," Chem. Engr. Sci., 6, pp. $89-93$ (1956).

15. Van der Laan, E. Th., "Notes on the Diffusion-Type Model for the Longitudinal Mixing in Flow," Chem. Engr. Sci., 7, 187-191 (1958).

16. Bischoff, K. B., "Notes on the Diffusion-Type Model for Longitudinal Mixing in Flow," Chem. Engr. Sci., 12, pp. 69-7.0 (1960).

17. Aris, R., "Notes on the Diffusion-Type Model for Longitudinal Mixing in Flow," Chem. Engr. Sci., 9, pp. 266-267 (1959).

18. Bischoff, K. B., "An Example of the Use of Combined Models: Mixing in a Tubular Vessel with Return Bends," A.I.Ch.E.J., 10, pp. 584-596 (1964).

19. Bischoff, K. 8., "The General Use of Imperfect Pulse Inputs to Find Characteristics of Flow Systems," Can. J. Chem. Engr., 41, p. 129 (1963).

20. Levenspiel, O., Chemical Reaction Engineering, pp. 242-301, John Wiley und Sunis, New York (1962).

21. Aris, R. and Amundson, N. R., "Some Remarks on Longitudinal Mixing or Diffusion in Fixed Beds," A.l.Ch.E.J., 3, pp. 280-282 (1957).

22. Levenspiel, O., "How Much Mixing Occurs in a Pipe?" Pet. Ref., 37, PP. 191-194 (1958).

23. Carslaw, H. S., Introduction to the Mathematical Theory of the Conduction of Heat in Solids, Second Edition, P. 153, Dover Publications, New York (1945).

24. Levenspiel, O., "Longitudinal Mixing of Fluids Flowing in Circular Pipes," Ind. Engr. Chem, , 50, pp. 343-346 (1958). 
25. Gunning, H. E. and Gordon, A. R., "The Conductance and lonic Mobilities for Aqueous Solutions of Potassium and Sodium Chloride at Temperatures from $15^{\circ}$ to $45^{\circ} \mathrm{C} ., " \mathrm{~J}$. Chem. Phy., 10, pp. 126-131 (1942).

26. International Critical Tables, Vol. 6, Part 1, Tables 1 and 2, pp. 231-239, McGraw-Hill Book Company, Inc., New York (1928).

27. Danckwerts, P. V., "Continuous Flow Systems," Chem. Engr. Sci., 2, pp. $1-13(1953)$.

28. Tichacek, L. J., Barkelew, C. H., and Baron, T., "Axial Mixing in Pipes," A.I.Ch.E.J., $\stackrel{3}{=}$, pp. 439-442 (1957).

29. McCabe, W. L. and Smith, J. C., Unit Operations of Chemical Engineering, McGraw-Hill Book Company, Inc., New York (1956).

30. Wilkinson, W. L., Non-Newtonial Fluids, p. 72, Pergamon Press, Ine., New York (1960).

31. Lehmann, E. L., Testing of Statistical Hypotheses, pp. 284-286, John Wiley and Sons, New York (1959).

32. Mickley, H. S., Sherwood, T. K., and Reed, C. E., Applied Mathematics in Chemical Engineering, Second Edition, pp. 148-155, McGraw-Hill Book Company, Inc., New York (1957). 
APPENDIX 


\section{METHOD FOR - TRANSFORMING ELECTRICAL CONDUCTIVITY DISTRIBUTIONS INTO DISPERSION INTENSITIES}

The equations used to transform electrical-conductivity distributions generated on recorder strip charts into dispersion intensities were the calibration equation giving tracer concentration as afunction of electrical conductivity (Equation 35, Page 40) and a relationship between the location of the conductivity curve, along the chart from an initial chart location, with time beginning at the start of the experiment. The time transformation was made using:

$$
t=\frac{D_{1}-D_{0}}{r}
$$

where:

$$
\begin{aligned}
& i=\text { time, } \\
& D_{1}=\text { displacement of the strip chart from the reference point to a point } \\
& \text { on the conductivity curve (inches), } \\
& D_{0}=\text { initial displacement on the strip chart from the reference point } \\
& \quad \text { (inches), and } \\
& r=\text { chart rate (inches/minute). }
\end{aligned}
$$

Because all measured mixing numbers were small, a simplified relationship between the mixing number and the dimensionless variance of the exit age distribution ${ }^{(27)}$ for pulse-type tracer experiments, as suggested by Levenspiel and Smith, (9) was used. This relationship: 


$$
\sigma^{2}=2 P
$$

was combined with a variance calculational method demonstrated by Levenspiel, ${ }^{(20)}$ namely:

$$
\begin{aligned}
& \sigma_{t}{ }^{2}=\frac{\Sigma(t-\eta)^{2} c \Delta t}{\Sigma c t}, \\
& \bar{t}=\frac{\Sigma t c \Delta t}{\Sigma c \Delta t},
\end{aligned}
$$

and

$$
\sigma^{2}=\frac{\sigma_{t}^{2}}{(\bar{f})^{2}}
$$

where:

$$
\begin{aligned}
\sigma_{t}^{2} & =\text { dimensioned variance, } \\
\sigma^{2} & =\text { dimensionless variance, } \\
\bar{\dagger} & =\text { mean residence time, } \\
c & =\text { experimentally measured exit-age distribution function, and } \\
\dagger & =\text { time interval. }
\end{aligned}
$$

Since Equation 44 gives the second moment of the exit-age distribution about the mean and is independent of the value of the mean, only that portion of the concentration-time distribution reflecting the flow of tracer past the measurement point was used to calculate the variance. Any background concentration in the bulk contents of a system (demineralized water), which appeared as a small but finite initial conductivity, was subtracted from the distribution of tracer 
concentration. As a consequence, the mean resident time, $\bar{F}$, used in these calculations was obtained from

$$
\bar{f}=\frac{V}{Q^{\prime}}
$$

where: -

$$
\begin{aligned}
& V=\text { system volume, and } \\
& Q=\text { volumetric flow rate through the system. }
\end{aligned}
$$

Variances were transformed to dispersion intensities, $\mathrm{Di}$, by using the following relation:

$$
D i=\left(\frac{L}{d}\right) P,
$$

since:

$$
P=\frac{D}{U L},
$$

and

$$
D i=\frac{D}{u d},
$$

where:

$$
\begin{aligned}
& L=\text { length of the tank, and } \\
& d=\text { diameter of the tank. }
\end{aligned}
$$

A combination of Equations 43 and 46 gives the desired form for pulse-type experiments, namely:

$$
\mathrm{Di}=1 / 2\left(\frac{\mathrm{L}}{d}\right) \frac{\sigma_{t}^{2}}{(\bar{t})^{2}}
$$


In an effort to determine the effect of the tank end flow conditions upon the measured dispersion intensity, two series of experiments were conducted using the experimental methods developed by Aris (17) and by Bischoff. (16) By these methods, the requirement for the injection of a "perfect pulse" having zero variance of tracer was relieved and tracer injection of any arbitrary form was used when the measurement was made at two downstream axial positions. For these series, dispersion intensity in the center section of a tank was measured. A simplification of the relationships between mixing number and the difference in tracer variance measured at the two axial positions for small mixing numbers, as suggested by Levenspiel, was invoked as in the case of "pulse injection". When this was done the result was:

$$
\Delta \sigma^{2}=2 P,
$$

where:

$$
\begin{aligned}
\Delta \sigma^{2}= & \text { difference in variance measured at two axial locations, and } \\
P= & \text { mixing number based upon the axial displacement between measure- } \\
& \text { ment locations. }
\end{aligned}
$$

The variance difference must be calculated by the following method:

$$
\begin{aligned}
& \Delta \sigma_{t}^{2}=\left(\sigma_{t}^{2}\right)_{2}-\left(\sigma_{t}^{2}\right), \\
& F=\frac{V_{1}-2}{Q} \text {, and }
\end{aligned}
$$


$\Delta \sigma^{2}=\frac{\Delta \sigma_{\dagger}^{2}}{(\varsubsetneqq)^{2}}$

where:

$\left(\sigma_{t}^{2}\right)_{1}=$ upstream dimensioned variance,

$\left(\sigma_{t}^{2}\right)_{2}=$ downstream dimensioned variance, and

$v_{1-2}=$ volume of system between méasurement locations:

Variance data for all experimental series have been tabulated in Table $V$,

Page 51. Mixing numbers determined by Equation 50 were transformed to dispersion intensities as before by use of Equation 48 .

As a consequence of the observed linear correlation between the logarithm of the dimensional variance and the logarithm of the recirculation rate, (Equation 36, Page 47) an alternate method of correlating dispersion infensity with Reynolds number could have been used to get Equation 38, Page 50. If this were done, the constants in Equation 5.4 for "pulse-type" experiments could be obtained from:

$$
\begin{aligned}
& a=\log \left[\frac{\left(1.448 \times 10^{-2}\right)\left(3.797 \times 10^{-3}\right)^{2-B}(10)^{A}}{(d / 12)^{3+B} L}\right] \text {, and } \\
& \beta=B-2 \text {. }
\end{aligned}
$$

For experiments using an arbitrary tracer injection form where variance is measured at two axial positions, the transformation cannot be so simply expressed. For this case the correlation would be: 


$$
\begin{aligned}
& \log (D i)=\log \left(\frac{3.603 \times 10^{3}}{d^{5} L_{1-2}}\right)+\log \left[10^{A_{2}}\left(3.797 \times 10^{-3} \operatorname{Re} d\right)^{2-B_{2}}-\right. \\
& \left.{ }_{10}^{A_{1}}\left(3.797 \times 10^{-3} \operatorname{Red}\right)^{2-B_{1}}\right]
\end{aligned}
$$

where Subscripts 1 and 2 carry the upstream and downstream measurement position fit constants from Equation 36, Page 47, and $L_{1-2}$ the axial distance between the measurement positions. 